\title{
DNA-Pairing and Annealing Processes in Homologous Recombination and Homology-Directed Repair
}

\author{
Scott W. Morrical \\ Department of Biochemistry, University of Vermont College of Medicine, Burlington, Vermont 05405 \\ Correspondence: scott.morrical@uvm.edu
}

The formation of heteroduplex DNA is a central step in the exchange of DNA sequences via homologous recombination, and in the accurate repair of broken chromosomes via homology-directed repair pathways. In cells, heteroduplex DNA largely arises through the activities of recombination proteins that promote DNA-pairing and annealing reactions. Classes of proteins involved in pairing and annealing include RecA-family DNA-pairing proteins, single-stranded DNA (ssDNA)-binding proteins, recombination mediator proteins, annealing proteins, and nucleases. This review explores the properties of these pairing and annealing proteins, and highlights their roles in complex recombination processes including the double Holliday junction (DhJ) formation, synthesis-dependent strand annealing, and singlestrand annealing pathways-DNA transactions that are critical both for genome stability in individual organisms and for the evolution of species.

\begin{abstract}
A central step in the process of homologous Arecombination is the formation of heteroduplex DNA. In this article, heteroduplex DNA is defined as double-stranded DNA that arose from recombination, in which the two strands are derived from different parental DNA molecules or regions. The two strands of the heteroduplex may be fully complementary in sequence, or may contain small regions of noncomplementarity embedded within their otherwise complementary sequences. In either case, WatsonCrick base pairs must stabilize the heteroduplex to the extent that it can exist as free DNA following the dissociation of the recombination proteins that promoted its formation.
\end{abstract}

The ability to form heteroduplex DNA using strands from two different parental DNA molecules lies at the heart of fundamental biological processes that control genome stability in individual organisms, inheritance of genetic information by their progeny, and genetic diversity within the resulting populations (Amunugama and Fishel 2012). During meiosis, the formation of heteroduplex DNA facilitates crossing-over and allelic exchange between homologous chromosomes; this process ensures that progeny are not identical clones of their parents and that sexual reproduction between individuals will result in a genetically diverse population (see Lam and Keeney 2015; Zickler

Editors: Stephen Kowalczykowski, Neil Hunter, and Wolf-Dietrich Heyer

Additional Perspectives on DNA Recombination available at www.cshperspectives.org

Copyright (C) 2015 Cold Spring Harbor Laboratory Press; all rights reserved; doi: 10.1101/cshperspect.a016444

Cite this article as Cold Spring Harb Perspect Biol 2015;7:a016444 
S.W. Morrical

and Kleckner 2015). Heteroduplex DNA generated by meiotic COs also ensures proper segregation of homologous chromosomes, so that each gamete receives a complete but genetically distinct set of chromosomes (BascomSlack et al. 1997; Gerton and Hawley 2005). In mitotic cells, heteroduplex DNA formation between sister chromatids is essential for homology-directed repair (HR) of DNA doublestrand breaks (DSBs), stalled replication forks, and other lesions (Maher et al. 2011; Amunugama and Fishel 2012; Mehta and Haber 2014). Prokaryotic organisms also generate heteroduplex DNA to perform HR transactions, and to promote genetic exchanges, such as occur dur- ing bacterial conjugation (Cox 1999; Thomas and Nielsen 2005).

Fundamentally, heteroduplex DNA generation involves the formation of tracts of WatsonCrick base pairs between strands of DNA derived from two different progenitor ( parental) DNA molecules. Mechanistically, the DNA transactions giving rise to heteroduplex may involve two, three, or four strands of DNA (Fig. 1). DNA annealing refers to heteroduplex formation from two complementary (or nearly complementary) molecules or regions of singlestranded DNA (ssDNA) (Fig. 1A). DNA annealing may occur spontaneously, but it is promoted in vivo by certain classes of annealing proteins.

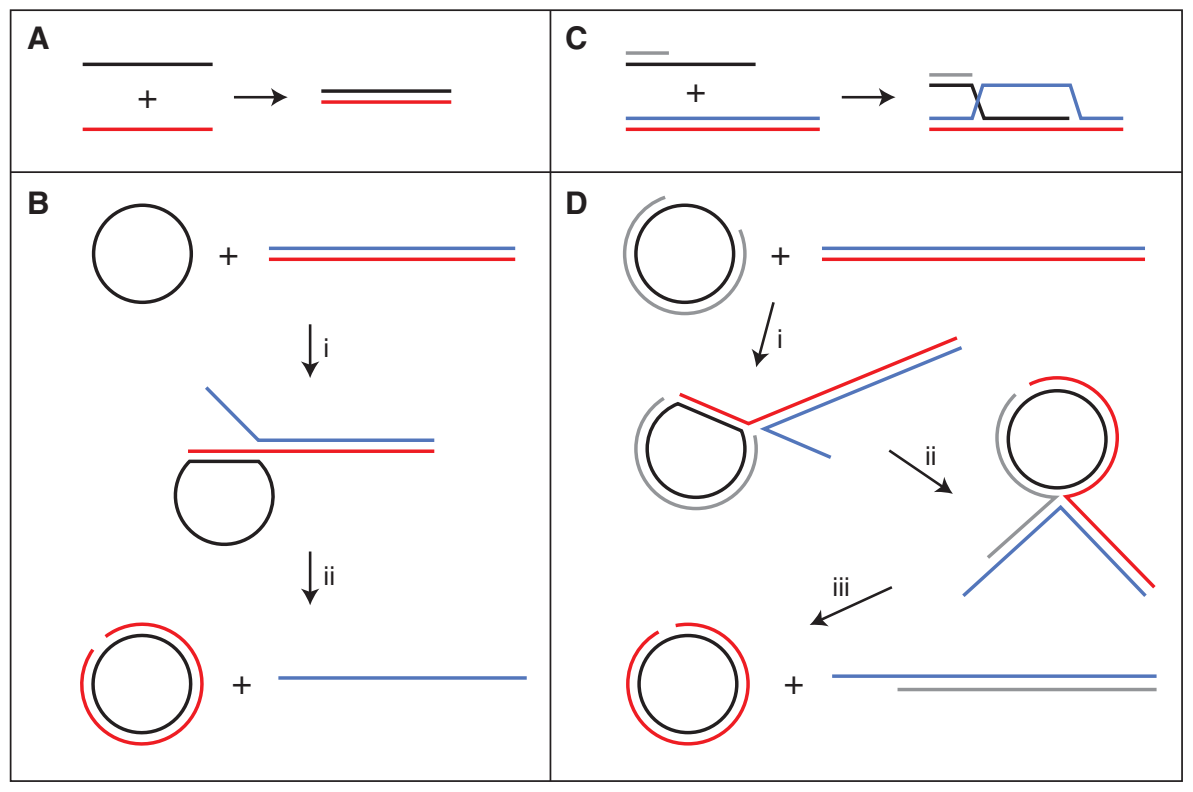

Figure 1. Common DNA annealing and pairing reactions. (A) Simple annealing between two complementary molecules of single-stranded DNA to form a heteroduplex. $(B)$ Three-stranded DNA-pairing reaction of the type used for in vitro assays of RecA-family DNA-pairing proteins. The single-stranded circle is homologous to the linear duplex. Formation of heteroduplex (red strand base-paired to black) requires protein-promoted invasion of the duplex by the ssDNA to form a joint molecule or D-loop (i). The length of the heteroduplex may be extended by branch migration (ii). (C) Three-stranded DNA-pairing reaction of the type used for high-fidelity repair of DNA DSBs in vivo. The invading strand is the ssDNA tail of a resected DSB. The $3^{\prime}$ end of the invading strand is incorporated into the heteroduplex within the D-loop intermediate. $(D)$ Example of a four-stranded DNA-pairing transaction that is initiated by a three-stranded pairing event and extended by branch migration. The ssDNA in a gapped duplex serves as the invading strand to generate a joint molecule (i), reminiscent of the reaction shown in panel $B$. Protein-directed branch migration may proceed into the duplex region adjacent to the original gap, generating $\alpha$-structure intermediates (ii), or eventually a complete exchange of strands (iii). 
Three-stranded reactions yielding heteroduplex DNA proceed by a different mechanism referred to as DNA pairing, strand invasion, or strand exchange. These reactions involve the invasion of a duplex DNA molecule by homologous (or nearly homologous) ssDNA. The invading DNA may be completely single stranded, as is often the case in in vitro assays for DNA-pairing activity (Fig. 1B) (Cox and Lehman 1981). Under physiological conditions, however, the invading ssDNA is contained as a single-stranded tail or gap within a duplex (Fig. 1C,D). DNA-pairing reactions are promoted by DNA-pairing proteins of the RecA family (Bianco et al. 1998), and proceed via the formation of D-loop or joint molecule intermediates that contain the heteroduplex DNA (Fig. 1B-D). Three-stranded reactions may also be promoted by exonuclease/annealing protein complexes found in certain viruses. Four-stranded reactions generating heteroduplex DNA involve branch migration of a Holliday junction (Fig. 1D). In practice, a four-stranded reaction must be initiated by a three-stranded pairing reaction catalyzed by a DNA-pairing protein, after which the heteroduplex is extended into duplex regions through the action of the DNA-pairing protein or of an associated DNA helicase/translocase (Das Gupta et al. 1981; Kim et al. 1992; Tsaneva et al. 1992).

\section{ROLES OF DNA PAIRING AND ANNEALING IN HR OF DNA DSBs}

HR of DSBs illustrates the biological significance ofDNA-pairing and annealing reactions (Fig. 2). The pairing and annealing components of these pathways are conserved across the phylogenetic spectrum (see Mehta and Haber 2014).

\section{The Double Holliday Junction Pathway of DSB Repair}

The double Holliday junction ( $\mathrm{dHJ}$ ) pathway, also referred to as the DSB repair (DSBR), crossover (CO), or gene conversion (GC) pathway, involves both pairing and annealing steps, and is the pathway used to generate meiotic COs (Szostak et al. 1983; Symington 2002; San Filippo et al. 2008). This process is illustrated in Figure 2A. Following resection of ends at a DSB (see Symington 2014), a pairing reaction occurs between the $3^{\prime}$ ssDNA tail of one end and the homologous duplex. In the resulting heteroduplex, the $3^{\prime}$ end of the invading strand primes DNA synthesis to extend the D-loop intermediate. Subsequently, in a process referred to as second-end capture (Nimonkar and Kowalczykowski 2009; Nimonkar et al. 2009), the displaced ssDNA in the D-loop undergoes an annealing reaction with the ssDNA tail of the remaining end, generating a second region of heteroduplex DNA that is also extended by DNA synthesis (Fig. 2A). Ligation generates a classic dHJ structure in which the regions of heteroduplex may be further extended by branch migration, resulting in the COs and extensive GC tracts associated with this pathway (Szostak et al. 1983).

\section{Synthesis-Dependent Strand Annealing}

The synthesis-dependent strand annealing (SDSA) pathway of HR also includes both pairing and annealing steps (Fig. 2B). Unlike the $\mathrm{dHJ}$ pathway, however, SDSA generates predominantly noncrossover (NCO) recombinants with relatively low frequencies of GC (Haber 1992; Ira et al. 2003). First inferred from studies of recombination in the T4 bacteriophage (Formosa and Alberts 1986; Mueller et al. 1996; Kreuzer 2000), SDSA appears to be the preferred mitotic HR pathway in higher eukaryotes (Andersen and Sekelsky 2010; Mitchel et al. 2013). Like $\mathrm{dHJ}$, the SDSA process begins with a pairing reaction between one of the resected ends of a DSB and the homologous duplex region of the sister chromatid. The heteroduplex/D-loop structure generated in SDSA is more dynamic than the one formed in $\mathrm{dHJ}$; however, DNA synthesis extends the heteroduplex in the $3^{\prime} \mathrm{di}-$ rection, but the heteroduplex is rapidly resolved by branch migration of the trailing edge of the D-loop (see Daley et al. 2014). The result is a Dloop that translocates along the sister duplex, and an extended invading strand that is only transiently associated with its template (Fig. 2B). Second-end capture, therefore, involves annealing of the second end not to the displaced strand of the D-loop as in $\mathrm{dHJ}$, but rather to the 
S.W. Morrical
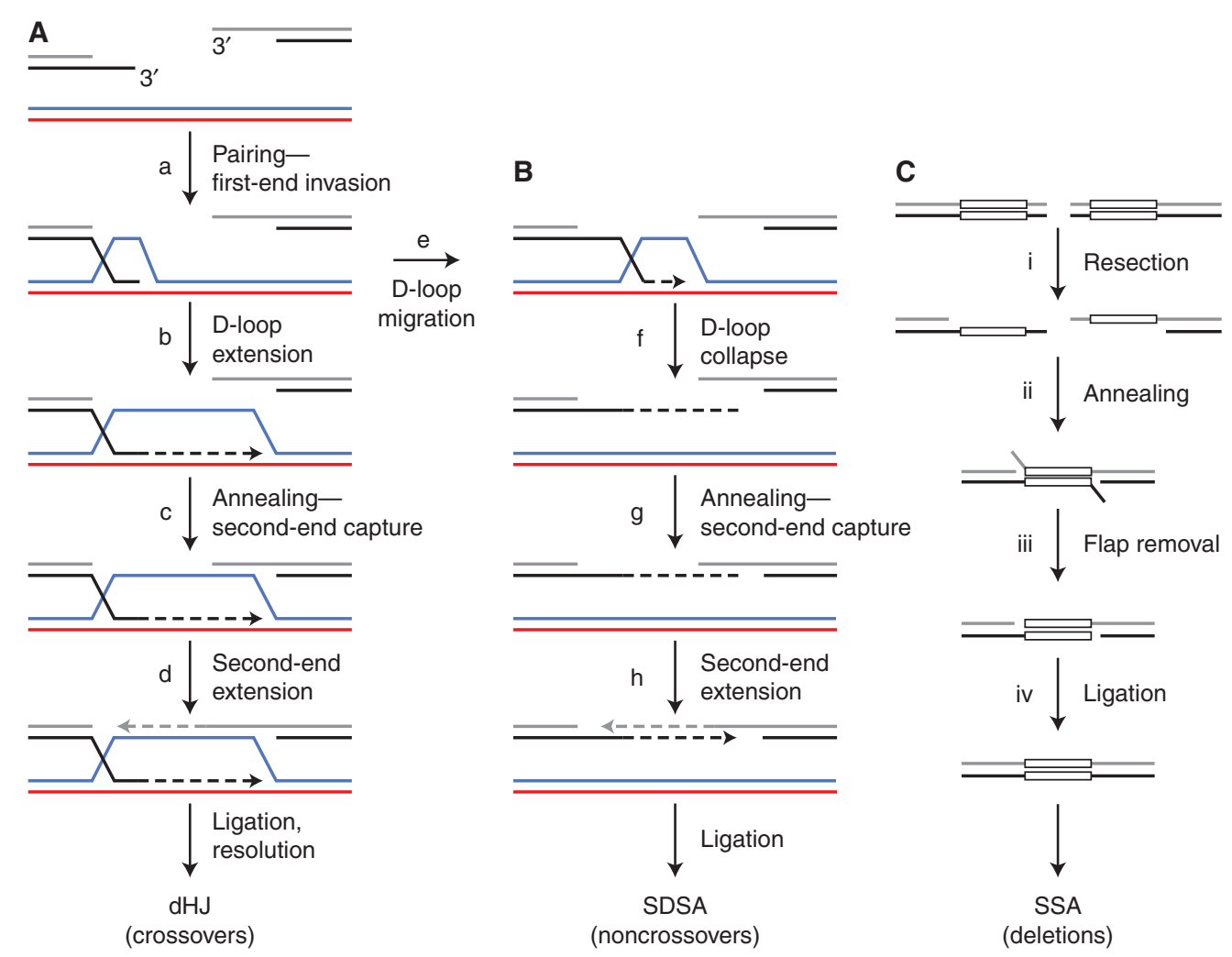

Figure 2. DNA-pairing and annealing steps in the repair of DNA DSBs. (A) The double Holliday junction (dHJ) pathway. A resected double-strand break (DSB) $3^{\prime}$ end (black) pairs with and invades a sister chromatid (blue/ red dotted) to generate a D-loop (a). DNA synthesis (dashed arrow) extends the D-loop (b), exposing ssDNA (blue) that is complementary to the $3^{\prime}$ ssDNA tail of the second resected DSB end (gray). The second end is captured by annealing (c), and extended by replication (d). Ligation generates the characteristic $\mathrm{dHJ}$, which may be cleaved by HJ resolvases into either CO or NCO products. (B) The synthesis-dependent strand annealing (SDSA) pathway. Pairing as in panel $A$ generates a D-loop that translocates owing to simultaneous replication and branch migration (e). The translocating D-loop is inherently unstable, leading to collapse as branch migration overtakes replication (f). The extended first end (black dashed line) may anneal to complementary ssDNA in the resected second end (gray), resulting in second-end capture (g). Replicative extension of both ends (black and gray dashed arrows) (h) and ligation generates NCO products. $(C)$ The single-strand annealing (SSA) pathway. Resection of a DSB that occurs between two direct sequence repeats (white boxes) exposes complementary sequences in the ssDNA tails of the two ends (i). The complementary portions anneal (ii), leaving flaps of noncomplementary ssDNA on the $3^{\prime}$ ends. Nucleolytic flap removal (iii) and ligation (iv) generates a deletion product lacking one of the repeats and the intervening sequence.

extended strand of the first end (Fig. 2B). This mechanism allows second-end capture without the formation of a CO. SDSA appears optimized for recombination between sister chromatids in $\mathrm{S} / \mathrm{G}_{2}$ cells, to promote high-fidelity repair of mitotic DSBs with lower risk of loss of heterozygosity (LOH). Evidence also suggests that meiotic GC events that are not associated with
COs occur via the SDSA mechanism (McMahill et al. 2007).

\section{Break-Induced Replication}

Break-induced replication (BIR) (see Mehta and Haber 2014) is a third type of HR transaction that is initiated by a pairing reaction be- 
tween the ssDNA tail of a resected end and the homologous duplex region of a sister chromatid (Llorente et al. 2008; Anand et al. 2013). There is no second-end capture by annealing in BIR, unlike in $\mathrm{dHJ}$ and SDSA. In BIR the heteroduplex/ D-loop structure is stable, but second-end capture fails owing to loss or inaccessibility of the second end. Instead, replicative extension of the invading strand is coupled to replisome assembly, resulting in the initiation of both leading and lagging strand DNA synthesis from the site of heteroduplex formation (Lydeard et al. 2010). The recombination-dependent replication pathway of bacteriophage T4 is an excellent example of BIR, which is used as the major mechanism for replicating the terminally redundant phage chromosome (Kreuzer and Brister 2010; Liu and Morrical 2010). BIR may proceed for many kilobases, resulting in extensive GC tracts or in the duplication of an entire chromosome arm. For this reason BIR is associated with extensive LOH (Sakofsky et al. 2012).

\section{Single-Strand Annealing}

In contrast to BIR, single-strand annealing (SSA) is an HR pathway that relies on annealing but not on pairing (Symington 2002). The SSA process is illustrated in Figure 2C. SSA is unique compared with the other HR pathways in that it does not require a homologous chromosome or sister chromatid for templating purposes. SSA is a mechanism for rejoining DNA ends when those ends contain direct sequence repeats (or near repeats). If a DSB occurs between the repeats, then resection of the ends can expose complementary sequences in the resulting ssDNA tails. These complementary ssDNA sequences anneal to form a heteroduplex, after which noncomplementary ssDNA "flaps" are removed, any gaps are filled in by new DNA synthesis, and nicks are ligated (Fig. 2C). SSA restores the continuity of the duplex; however, the repair process is mutagenic because deletions are introduced in the DNA sequence. (One copy of the repeated sequence is deleted, along with all sequences that were located between the original repeats.) Thus, SSA is an error-prone, intrachromosomal recombination process that relies exclusively on two-stranded annealing reactions to generate heteroduplex. In contrast, $\mathrm{dHJ}$, SDSA, and BIR are high-fidelity, interchromosomal recombination processes that rely on three-stranded pairing reactions for the first round of heteroduplex formation. The latter three pathways avoid the deletion mutations that occur during SSA by using the homologous chromosome or sister chromatid as a template for repair synthesis.

\section{PROPERTIES OF DNA-PAIRING PROTEINS}

Classic pathways of homologous recombination and HR involve a core set of proteins that promote DNA-pairing reactions, including a RecAfamily DNA-pairing protein, ssDNA-binding protein, and recombination mediator proteins (San Filippo et al. 2008; Liu et al. 2011a; Zelensky et al. 2014). In Saccharomyces cerevisiae, most of these proteins are encoded by genes in the RAD52 epistasis group, and the key players are highly conserved across all kingdoms of life (Symington 2002). Here, we explore some of the properties of these proteins, and how their pairing and annealing activities contribute to DNA recombination/repair pathways including $\mathrm{dHJ}$, SDSA, BIR, and SSA.

\section{Classic DNA-Pairing Proteins: The RecA Family}

DNA-pairing reactions required for $\mathrm{dHJ}$, SDSA, and BIR repair pathways are promoted by DNApairing proteins of the highly conserved RecA family (Table 1). This enzyme family has representatives in all kingdoms of cellular life as well as in viruses. Well-characterized representatives include the Escherichia coli RecA protein in prokaryotes, the bacteriophage T4 UvsX protein in viruses, the $S$. cerevisiae and Homo sapiens Rad51 proteins in eukaryotes, and the Sulfolobus solfataricus RadA protein in archaea. Eukaryotic Dmcl proteins are meiosis-specialized paralogs of the Rad51 DNA-pairing protein. The physical and biochemical properties of these and related enzymes have been reviewed extensively elsewhere (Bianco et al. 1998; Shin et al. 2004; Liu et al. 2011a). 
S.W. Morrical

Table 1. Representative pairing and annealing proteins

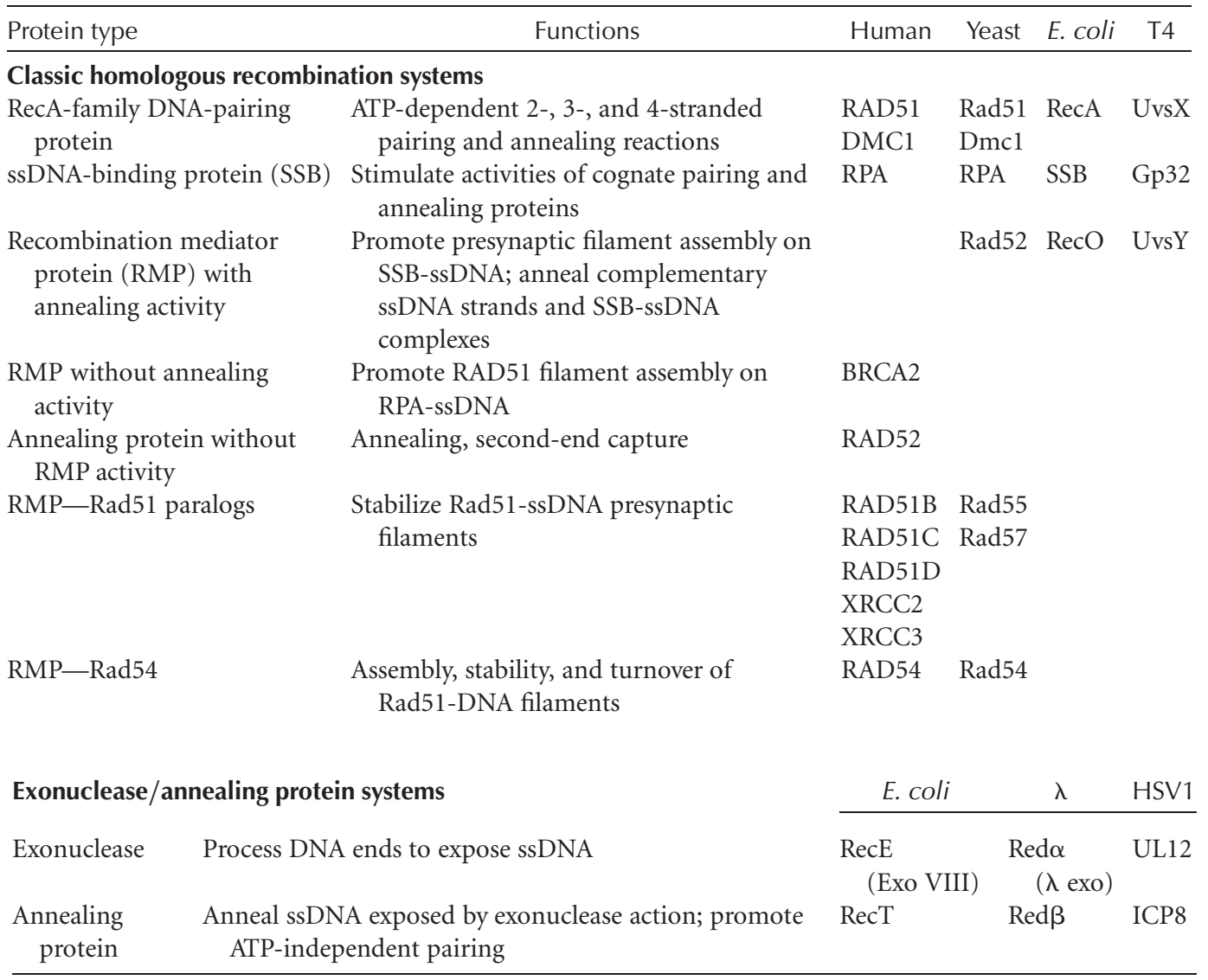

All DNA-pairing proteins of the RecA family share a common protein fold in their catalytic core domains (Story et al. 1992; Pellegrini et al. 2002; Conway et al. 2004; Wu et al. 2004; Chen et al. 2008, 2010; Gajewski et al. 2011), which corresponds to the region of highest amino acid sequence identity/similarity between divergent orthologs. This region includes the Walker A and B motifs as well as DNA-binding loops designated L1 and L2. Structural details of the RecA fold appear in Schiller et al. (2014). Species-specific amino- and carboxy-terminal extensions found in different DNA-pairing proteins, such as the large amino-terminal extension found in yeast Rad51, or the carboxy-terminal domain of E. coli RecA, contain binding sites for accessory proteins or perform other regulatory functions. All RecA-family DNA-pairing proteins form fil- aments on ssDNA in the presence of ATP, which are referred to as presynaptic filaments for their role as precursors to synapsis (homologous pairing). The architectural framework of presynaptic filaments is highly conserved, consisting of an open, right-handed helix, with each helical turn containing six protein monomers bound to a total of 18 nucleotides (base pairs) of ssDNA (dsDNA) (Chen et al. 2008). The DNA is bound via interactions with loops L1 and L2 to the inner filament surface, with ATP-binding sites located at the interfaces between subunits (Conway et al. 2004; Chen et al. 2008). Presynaptic filament assembly activates the catalytic activities of the DNA-pairing protein, including ATP hydrolysis, plus ATP-dependent pairing and strand exchange reactions with a homologous duplex. The binding and hydro- 
lysis of ATP modulates the structure of presynaptic filaments between ATP-bound "active" and ADP-bound or nucleotide-free "inactive" conformations: The active filament has a high helical pitch in which the bound DNA is significantly stretched (helical pitch of 95-99 $\AA$, depending on species), whereas the inactive filament has a low helical pitch $(70-76 \AA$, depending on species) (Griffith and Formosa 1985; Yu and Egelman 1992, 1993; Ogawa et al. 1993; Yang et al. 2001; Yu et al. 2001). These and other factors influencing the dynamics of presynaptic filaments are the subject of a recent review (Liu et al. 2011a).

DNA-pairing proteins also form filaments on double-stranded DNA, either through intrinsic dsDNA-binding activity, or in the course of DNA-pairing reactions (Pugh and Cox 1987a,b; Zaitseva et al. 1999; Solinger et al. 2002). Intrinsic DNA-pairing protein-dsDNA-binding activities vary significantly between species: For example, E. coli RecA protein forms filaments on dsDNA only at low $\mathrm{pH}$ or when the duplex contains regions of ssDNA or other structural distortions (McEntee et al. 1981; Pugh and Cox 1987a, 1988; Rosenberg and Echols 1990). Once assembled, however, RecA-dsDNA filaments show high rates of ATP hydrolysis. In contrast, the T4 UvsX protein binds spontaneously to dsDNA, but the resulting UvsX-dsDNA complexes do not have ATPase activity (Maher and Morrical 2013). Eukaryotic Rad51 enzymes also bind spontaneously to dsDNA, but the resulting complexes are inhibitory toward DNA pairing if they are allowed to form before the introduction of ssDNA (Sung and Robberson 1995; Solinger et al. 2002). The redirection of a duplex-bound DNA-pairing protein into pairing-competent presynaptic filaments is accomplished by species-specific mechanisms involving the actions of accessory proteins. For example, the Swi2/Snf2-related Rad54 protein disassembles Rad51-dsDNA complexes to relieve the inhibition of DNA pairing (Solinger et al. 2002; Li et al. 2007). Alternatively, recovery from dsDNA may involve ligand-induced allosteric effects on the DNA-pairing protein itself. This is observed with the T4 UvsX protein, in which ATPase-inactive complexes on dsDNA are rapidly activated for DNA strand exchange by the addition of homologous, but not of heterologous, ssDNA (Maher and Morrical 2013).

To carry out pairing reactions, DNA-pairing protein filaments must interact with two DNA molecules simultaneously. Presynaptic filament assembly on ssDNA also reconstitutes a secondary DNA-binding site that can accommodate either ssDNA or dsDNA (Mazin and Kowalczykowski 1996, 1998). Two-stranded annealing reactions may occur when the secondary site is occupied by a complementary ssDNA molecule, as has been observed with E. coli RecA, T4 UvsX, human RAD51, and other enzymes (Bryant and Lehman 1985; McEntee 1985; Yonesaki and Minagawa 1989; Gupta et al. 1997). Pairing and strand exchange occurs when homologous duplex DNA binds to the secondary site (Mazin and Kowalczykowski 1998). DNA-pairing proteins by definition are proficient in ATP-dependent three-stranded pairing reactions, the typical in vitro assay for which is shown in Figure 1B. The distribution of heteroduplex products differs from enzyme to enzyme, however (Liu et al. 2011a). E. coli RecA contains a robust branch migration activity that converts D-loop pairing intermediates into extended heteroduplex products (Fig. 1B) (Cox and Lehman 1981). Eukaryotic Rad51 enzymes are much less efficient in promoting branch migration; therefore, heteroduplex joint molecules tend to accumulate (Sung 1994; Baumann et al. 1996). In contrast, T4 UvsX has a promiscuous pairing activity that generates branched networks of ssDNA and dsDNA (Kodadek et al. 1988).

All pairing and annealing reactions promoted by RecA-family DNA-pairing proteins are ATP dependent. Evidence indicates that pairing activity requires ATP binding but not ATP hydrolysis (Menetski et al. 1990). This reflects the requirement for ATP binding to induce the extended, active form of the presynaptic filament. On the other hand, ATP hydrolysis appears to regulate filament activity and to provide for filament turnover or dynamic instability (Kowalczykowski 1991; Cox 2003; Liu et al. 2006, 2011a). In addition, DNA-pairing protein-promoted pairing reactions are stimulated by ssDNA-binding and recombination mediator 
S.W. Morrical

proteins, which are described below (see Daley et al. 2014; Zelensky et al. 2014).

\section{ssDNA-Binding Proteins}

ssDNA-binding proteins, or SSBs, are ubiquitous proteins that play fundamental roles in DNA recombination, replication, and repair, as well as in DNA damage signaling, cell-cycle control, and regulation of gene expression (Wold 1997; Lohman et al. 1988; Lohman and Ferrari 1994; Binz et al. 2004; Bochkarev and Bochkareva 2004; Richard et al. 2009). Well-characterized examples include E. coli SSB protein, bacteriophage T4 Gp32 protein, and the RPA proteins of yeast and humans (Table 1). Common properties of SSBs include stoichiometric, sequence nonspecific binding to ssDNA, highaffinity and (typically) cooperative binding to ssDNA, weak or nonexistent affinity for dsDNA, and the ability to stimulate cognate replication and recombination enzymes. SSBs all contain one or more copies of the oligonucleotide/oligosaccharide-binding (OB) fold motif (Arcus 2002; Bochkarev and Bochkareva 2004). SSB sequences are divergent, however, and their tertiary structures vary dramatically between species. For example, the fundamental ssDNA-binding units of T4 Gp32, E. coli SSB, and eukaryotic RPA proteins are monomers, homotetramers, and heterotrimers, respectively. Stoichiometric and cooperative binding allows SSBs to saturate regions of ssDNA, which maintains the DNA in an unwound state, protects it from inappropriate degradation by nucleases, denatures ssDNA secondary structure, and optimizes ssDNA structure for recognition by other recombination and replication proteins. These properties allow SSBs to perform key functions in both DNA-pairing and DNA-annealing reactions, as described below.

SSB proteins participate directly in threestranded pairing reactions promoted by the cognate RecA-family DNA-pairing proteins (Fig. 3) (Bianco et al. 1998; Liu et al. 2011a). SSBs stimulate these reactions by at least two different mechanisms: First, SSBs facilitate presynaptic filament assembly on ssDNA. The SSB removes secondary structure from ssDNA, optimizing its conformation for handoff to the DNA-pairing protein, a transaction that typically requires a cognate recombination mediator protein in addition to DNA-pairing protein and ATP (Umezu et al. 1993; Sung 1997b; Sugiyama and Kowalczykowski 2002; Liu et al. 2006) (see below). Second, SSBs stabilize the D-loop product of the pairing reaction by sequestering the displaced strand (Kodadek 1990). SSB proteins also stimulate two-stranded annealing reactions that are promoted by cognate recombination mediator proteins of the type described in the following section (Sugiyama et al. 1998; Kantake et al. 2002). For these reasons SSBs are seen as important for both the first-end invasion and second-end capture steps of the error-free $\mathrm{dHJ}$ and SDSA pathways, as well as for the annealing step of the mutagenic SSA pathway.

\section{Recombination Mediator Proteins}

Recombination mediator proteins, or RMPs, are defined as proteins that promote presynaptic filament assembly or that stabilize presynaptic filaments on ssDNA in the presence of cognate SSB (Beernink and Morrical 1999; Liu et al. 2011a; Zelensky et al. 2014). The diversity of known proteins that perform this function is growing; examples include (Table 1) the following.

\section{Annealing Proteins with RMP Activity}

These are DNA-binding proteins that show strong affinity for cognate SSB-ssDNA (Umezu and Kolodner 1994; Sweezy and Morrical 1999; Beernink and Morrical 1998; Sugiyama and Kowalczykowski 2002), and that lack any sequence homology with the RecA family. They possess intrinsic annealing activities (discussed below) that play separate and distinct roles in recombination from RMP activity (Kantake et al. 2002). Well-characterized examples include the T4 UvsY (Harris and Griffith 1989; Kodadek et al. 1989; Yonesaki and Minagawa 1989; Morrical and Alberts 1990; Hashimoto and Yonesaki 1991), E. coli RecO (Umezu and Kolodner 1994; Shan et al. 1997; Morimatsu and Kowalczykowski 2003), and S. cerevisiae Rad52 proteins 
DNA Pairing and Annealing

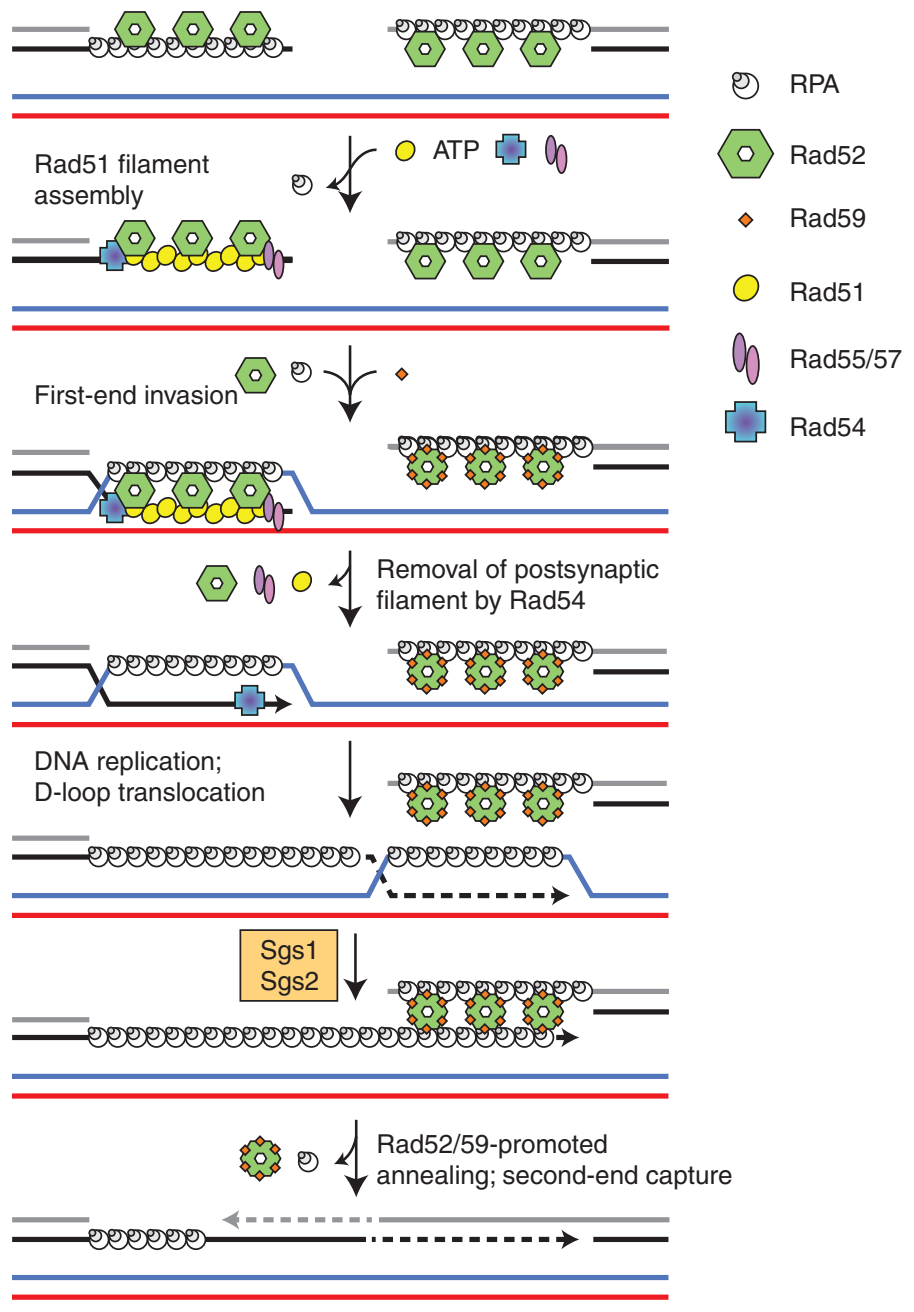

Figure 3. Model for the molecular mechanism of synthesis-dependent strand annealing (SDSA). S. cerevisiae proteins are shown. Resected DSB ends are bound by a complex of RPA and Rad52 proteins. Rad52 recruits Rad51 DNA-pairing protein and promotes presynaptic filament assembly on one of the resected ends. Rad54 and Rad55/57 proteins stabilize the presynaptic filament. The filament continues to interact with Rad52, suppressing the latter protein's annealing activity. Rad51 promotes homologous pairing and strand invasion of the first end to its homologous sequence in the sister chromatid. The resulting heteroduplex is covered with a postsynaptic filament of Rad51. Removal of this filament via the activity of Rad54 protein allows replication proteins to access the $3^{\prime}$ end of the invading strand and to initiate DNA synthesis. Translocation of the D-loop extends and releases the invading strand from the heteroduplex. Rad52 and Rad59 promote annealing and second-end capture. Replicative extension and ligation of the annealed strands completes the repair process, which generates NCO products exclusively.

(Sung 1997b; New et al. 1998; Song and Sung 2000; Sugiyama and Kowalczykowski 2002). UvsY, RecO, and Rad52 participate directly in three-stranded pairing reactions (Fig. 3). Their primary role is to facilitate the formation of presynaptic filaments on SSB-covered ssDNA by promoting the displacement of SSB by the incoming strand exchange protein (Liu et al. 2011a). For example in the T4 recombination system, UvsY binds tightly to Gp32-covered ssDNA, where it promotes the nucleation of UvsX-ssDNA presynaptic filaments with con- 
S.W. Morrical

comitant displacement of Gp32 from ssDNA (Liu et al. 2006, 2013). The yeast Rad52 protein promotes a similar exchange of Rad51/RPA proteins on ssDNA during presynapsis (Sugiyama and Kowalczykowski 2002), and this mechanism likely applies to all RMPs of this subclass. This conserved activity is important for pairing reactions in mitotic dHJ, SDSA, and BIR pathways, and likely in meiotic recombination.

\section{BRCA2}

Human BRCA2 protein performs the classic RMP function of loading RAD51 protein onto RPA-covered ssDNA (Jensen et al. 2010; Liu et al. 2010). It appears that BRCA2 has superseded RAD52 as the major RMP used for presynpatic filament assembly and to promote DNA pairing in humans (Liu et al. 2011a). Unlike RAD52, BRCA2 does not promote the annealing of complementary RPA-covered ssDNA strands (Jensen et al. 2010). Therefore, there appears to be a division of labor between the human BRCA2 and RAD52 proteins, with the former specialized for presynaptic roles leading to first-end invasion, and the latter specialized for roles in annealing, second-end capture, and SSA. This stands in contrast to the budding yeast system, which lacks BRCA2 and, therefore, uses Rad52 both as a mediator of Rad51-promoted pairing and as the major annealing protein used for second-end capture and SSA (Fig. 3) (Nimonkar et al. 2009).

\section{Rad51 Paralogs}

The S. cerevisiae Rad55 and Rad57 proteins are the best-characterized examples of this group, which also includes the human RAD51B, RAD51C, RAD51D, XRCC2, and XRCC3 proteins. The mechanism of Rad51 paralog RMP activity is still poorly defined, but appears to differ substantially from RMP/annealing proteins, such as UvsY, RecO, and Rad52. Recent studies of Rad55 and Rad57 proteins indicate that these RMP proteins, which together form a heterodimer, promote homologous pairing by stabilizing Rad51-ssDNA presynaptic filaments against dissociation that is caused either by spontaneous filament turnover linked to the ATPase cycle, or by the action of antirecombination helicases, such as Srs2 (Fig. 3) (Sung 1997a; Liu et al. 2011b). The fact that Rad55 and Rad57 are both Rad51 paralogs suggest that they could cap the ends of presynaptic filaments, or be integrated into the interiors of filaments, an idea that is supported by EM observations (Liu et al. 2011b). The five human Rad51 paralogs associate into two different complexes-the heterotetrameric BCDX2 (RAD51B-RAD51CRAD51D-XRCC2) complex, and the heterodimeric CX3 (RAD51C-XRCC3) complex (Masson et al. 2001). Both are observed to form ringshaped complexes on DNA and to bind with high specificity to Holliday junctions and other branched DNA structures (Compton et al. 2010).

\section{Rad54}

Rad54 is an ATP-dependent DNA translocase that plays multifaceted roles in homologous recombination (Heyer et al. 2006; Ceballos and Heyer 2011). Evidence indicates that Rad54 acts at the presynaptic step by stabilizing Rad51ssDNA presynaptic filaments (Fig. 3) (Mazin et al. 2003). Other evidence indicates that Rad54 also acts downstream from filament assembly (Van Komen et al. 2002; Raschle et al. 2004). Recent studies showed that Rad54 may disrupt the postsynaptic filament of $\operatorname{Rad} 51$ that is bound to the heteroduplex DNA - a key step in the recruitment of DNA replication machinery that is needed for D-loop extension ( $\mathrm{dHJ}$, BIR) or translocation (SDSA) (Li and Heyer 2009).

\section{DNA-ANNEALING PROTEINS IN HR}

Annealing between complementary strands of ssDNA is a central process in the SSA pathway, and is also critical for second-end capture during HR involving $\mathrm{dHJ}$ formation or SDSA (Fig. 2). The ability to anneal two complementary strands of ssDNA constitutes a separate and distinct function of certain proteins with recombination mediator activity including $S$. cerevisiae Rad52, E. coli RecO, and T4 UvsY (Yonesaki 
and Minagawa 1989; Mortensen et al. 1996; Reddy et al. 1997; Kantake et al. 2002). A remarkable and conserved activity of these proteins is their ability to anneal complementary ssDNA strands that are complexed with cognate ssDNA-binding protein (RPA, SSB, or Gp32, respectively) (Shinohara et al. 1998; Sugiyama et al. 1998; Kantake et al. 2002). This activity is important for the second-end capture phases of $\mathrm{dHJ}$ and SDSA pathways, as described below. The mechanism of Rad52-promoted annealing of RPA-ssDNA complexes involves the formation of a ternary Rad52-RPA-ssDNA complex (Shinohara et al. 1998; Sugiyama et al. 1998). This mechanism appears to be conserved as both RecO and UvsY show similar interactions with cognate SSB-ssDNA complexes (Sweezy and Morrical 1999; Ryzhikov et al. 2011; Ryzhikov and Korolev 2012).

The annealing activity of $S$. cerevisiae Rad52 protein is stimulated by Rad59, a paralog of Rad52 (Davis and Symington 2001; Wu et al. 2006). Rad59 has its own intrinsic annealing activity that is kinetically distinct from Rad52 (Wu et al. 2006). Unlike Rad52, the annealing activity of Rad59 is not stimulated by RPA (Petukhova et al. 1999; Wu et al. 2006). Rad59 also lacks recombination mediator activity, but it is biologically important in recombination pathways that do not require Rad51, such as SSA (Sugawara et al. 2000; Pannunzio et al. 2008, 2010). Rad59 conceivably acts as an accessory protein for annealing reactions promoted by Rad52 during the second-end capture phases of $\mathrm{dHJ}$ and SDSA.

Human RAD52 promotes annealing but is unable to promote RPA displacement from ssDNA by RAD51 (McIlwraith et al. 2000). Therefore, human RAD52 lacks the recombination mediator protein activity of the yeast Rad52 ortholog. In humans, RPA displacement by RAD51 is promoted instead by BRCA2 (Jensen et al. 2010; Liu et al. 2010); thus, there has been a specialization of function in human RAD52 compared with yeast Rad52, with the former likely reserved for SSA and second-end capture events. Like yeast Rad52, human RAD52 anneals complementary ssDNA strands coated with RPA (Grimme et al. 2010). The mechanism of an- nealing involves the simultaneous interaction of ring-shaped RAD52 oligomers with two strands of ssDNA or RPA-ssDNA. Within these complexes, wrapping of ssDNA around the RAD52 rings induces a conformation of ssDNA that is favorable for annealing (Grimme et al. 2010). RAD52-RPA protein-protein interactions and posttranslational modifications may also play important roles in the annealing of complementary RPA-ssDNA complexes. For example, phosphorylated RPA, on interaction with RAD52, induces the handoff of ssDNA from RPA to RAD52 (Deng et al. 2009). This suggests that there is a pathway for coupling the initiation of SSA or other annealing-dependent recombination processes to DNA damage signaling.

\section{COORDINATION OF PROTEIN ACTIVITIES DURING DSBR BY SYNTHESIS-DEPENDENT STRAND ANNEALING}

The SDSA pathway serves to illustrate the coordination that is necessary between different pairing and annealing proteins to bring about the desired high-fidelity repair of a DSB without introducing potentially genotoxic COs. Key steps in the pathway and roles of the major protein players are illustrated in Figure 3, using examples from the recombination system of the budding yeast $S$. cerevisiae. After the resection of DSB ends by the MRX nuclease complex and associated machinery (Mimitou and Symington 2009; see Symington 2014), the exposed $3^{\prime}$ ssDNA tails are sequestered by RPA protein, which controls the access of other recombination and replication proteins to the ssDNA. The next critical step in SDSA is the assembly of a presynaptic filament of Rad51 DNA-pairing protein on one of the RPA-covered ssDNA tails, which will be designated as the "first end." The loading of Rad51 and displacement of RPA from ssDNA requires ATP and the mediator activity of Rad52 protein, which binds tightly to the RPA-ssDNA complex (Fig. 3) (Davis and Symington 2003). From this position, Rad52 directs filament assembly by promoting Rad51/RPA exchange. The resulting presynaptic filament may be stabilized against 
S.W. Morrical

inappropriate dissociation through the mediator activities of Rad54 and Rad55/57 proteins. The Rad51 filament continues to interact with Rad52 via protein-protein interactions ( $\mathrm{Wu}$ et al. 2008). The Rad51 filament now promotes pairing and invasion of the first end to its homologous sequence on the sister chromatid (Fig. 3).

Following strand invasion, Rad51 remains associated with the heteroduplex DNA in a postsynaptic filament that plays several important roles (Fig. 3). First, the postsynaptic filament stabilizes the D-loop against dissolution caused by spontaneous branch migration or by the premature action of a DNA helicase. Second, the postsynaptic filament blocks premature extension of the D-loop by replication proteins. Third, Rad51 in the postsynaptic filament interacts locally with Rad52 and suppresses its annealing activity (Fig. 3) (Wu et al. 2008). The latter effect suppresses the formation of $\mathrm{dHJ}$ and, thus, avoids accidental formation of genotoxic COs. In response to appropriate signals, Rad54 eventually removes Rad51 from the heteroduplex (Li and Heyer 2009; Wright and Heyer 2014), which allows replication proteins to access and extend the invading first strand. This also releases Rad52 to participate in downstream annealing events.

An unstable D-loop is the hallmark of SDSA, which requires the active unwinding of the invading strand from its template, D-loop translocation, and eventually D-loop collapse to release the elongated first end as single-stranded DNA (Fig. 3). Evidence suggests that in yeast cells, the DNA helicases Sgs1 and Srs2 promote the formation of NCOs via SDSA, and also suppress COs by dismantling Holliday junctioncontaining intermediates (Ira et al. 2003; Miura et al. 2012; Daley et al. 2013, 2014; Mitchel et al. 2013). Sgs1 promotes the dissolution of $\mathrm{dHJ}$ structures in collaboration with Top3 and Rmil (Cejka et al. 2010; Hickson and Mankouri 2011; Mankouri et al. 2011). Srs2 is proposed to dismantle nicked HJ structures (Mitchel et al. 2013). Srs2 is stimulated by Rad51 to remove Rad51 from dsDNA, suggesting that Srs2 could promote SDSA by destabilizing D-loops ( Dupaigne et al. 2008). Thus, multiple helicases play- ing different, distinct roles are required to promote SDSA at the expense of COs.

The extended ssDNA tail that is generated as the result of D-loop translocation and dissolution is rapidly sequestered by RPA, which can attract Rad52. This Rad52 is no longer inhibited by the presence of a Rad51 filament, owing to turnover of the latter catalyzed by Rad54. Therefore, Rad52 is free to promote annealing between the elongated first end and the second end, an activity that may be stimulated by its accessory protein, Rad59 (Fig. 3) (Davis and Symington 2003). The result is second-end capture (Davis and Symington 2001; Wu et al. 2006, 2008) and the completion of DSBR by the NCO mechanism. In summary, sequential handoffs and coordinated activities between DNA-pairing and annealing proteins and their partners explain how SDSA effects the repair of DNA DSBs while minimizing risks associated with $\mathrm{COs}$ and $\mathrm{LOH}$.

\section{MECHANISM OF RecA-PROMOTED HOMOLOGOUS PAIRING}

\section{Target Location}

The efficacy of SDSA and other HR processes depends on the ability of a presynaptic filament containing a few hundred to a few thousand nucleotides of DNA-pairing protein-bound ssDNA to locate a homologous target sequence within a sister chromatid containing many millions of base pairs of dsDNA. Until recently, the mechanism by which presynaptic filaments find their target sequence was unknown. The complexity of the problem, and large diffusion coefficients of the reactants, argued for some manner of facilitated diffusion. Recent singlemolecule studies of E. coli RecA protein provided detailed evidence for a facilitated search mechanism called "intersegmental contact sampling” (Forget and Kowalczykowski 2012). An illustration of this mechanism is shown in Figure 4. The mechanism hinges on the fact that dsDNA that is not under tension exists as randomly coiled domains in three-dimensional space, and that random fluctuations occasionally bring distant segments of the linear sequence 

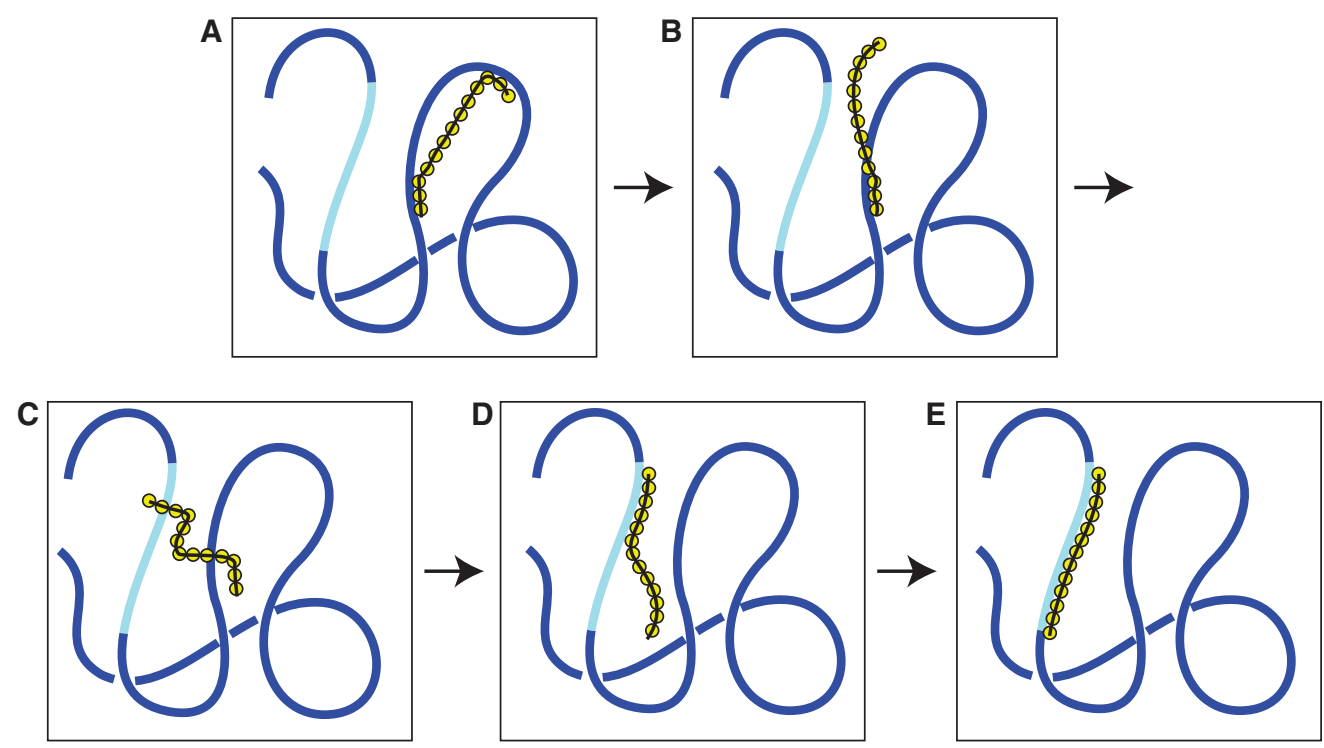

Figure 4. An illustration of the intersegmental contact sampling model for homology searches performed by RecA-ssDNA filaments. (A) A three-dimensional domain of randomly coiled duplex DNA (thick royal blue line) contains a target sequence (thick, cyan line) for homologous pairing with RecA-covered ssDNA (small yellow circles connected by a thin black line). The polyvalent RecA-ssDNA filament makes multiple weak contacts with nontarget sequences in the duplex. $(B)$ Filament contacts with nontarget duplex are unstable and rapidly dissociate, allowing facilitated diffusion of filament segments to other distant parts of the duplex. $(C)$ When a segment of the filament contacts homologous duplex, it forms a stable complex that effectively anchors that segment to the target site. This greatly increases the probability that other filament segments will diffuse to a homologous sequence after they dissociate from nontarget DNA $(D)$. (E) Propagation of this effect leads to the complete localization of the filament at its target sequence.

into closer proximity. The RecA-ssDNA filament may be thought of as a polymer of weakly sequence-specific binding sites for dsDNA. This property means that the filament may interact nonspecifically with and "bridge" multiple segments of the duplex that are brought together by three-dimensional diffusion. In this way the filament may sample and release many different segments of the duplex while searching through a relatively small volume (Fig. 4A-D). The most stable contacts occur between filament segments and duplex segments of the correct sequence homology, however. Finding one or a few sequence matches, therefore, constrains the search and greatly increases the probability of other filament segments locating regions of homology in the duplex. As the number of correct matches increases, and correspondingly the cumulative strength of the interactions, the free energy of the system is minimized and the filament is effec- tively localized at its target (Fig. 4E). The intersegmental contact sampling model potentially explains how RecA can pair sequences containing mismatches (Bazemore et al. 1997), because the increase in the energy minimum would be damped by multiple favorable contacts surrounding the sites of local heterology. Likewise, the ability of filaments to bridge distant segments of the duplex could explain how RecA pairs sequences containing heterologous inserts or deletions (Morel et al. 1994).

\section{Homology Detection and Strand Exchange}

The mechanism(s) by which homologous sequences in the target duplex are detected by the RecA-ssDNA filament, and subsequently driven to exchange strands to form a heteroduplex, have been argued for decades. In recent years there has been some convergence toward 
S.W. Morrical

the idea that the filament senses both WatsonCrick base pairing and DNA conformation in the recognition process, a mechanism referred to as "conformational proofreading" (Lee et al. 2006; Takahashi et al. 2007; see comments in Rambo et al. 2010; Savir and Tlusty 2010; Ragunathan et al. 2011). The atomic structure of the RecA-ssDNA filament, in its active, ATP-bound form, reveals that the ssDNA exists in a deformed conformation, with the sugar-phosphate backbone extended between trinucleotide units, which are held in a B-like conformation (Chen et al. 2008; see comments by Kowalczykowski 2008). Thus, the targeted duplex sequence must undergo a large conformational change to match both the Watson-Crick base pairing and local conformational requirements imposed by the RecA-ssDNA filament. The stringency of conformational proofreading, therefore, derives from the combined free energies of sequence-specific binding and deformation of the duplex. ATP hydrolysis is not needed for either step, because the spontaneous breathing of the duplex appears to sample all of the required conformational space (Savir and Tlusty 2010). Rapid kinetics data support the idea that the RecA-ssDNA filament binds to a deformed conformation of the duplex in which the sequence may be sampled via the formation of Watson-Crick base pairs (Lee et al. 2006). The propagation of heteroduplex formation occurs in three-base-pair increments (Ragunathan et al. 2011), consistent with the organization of the ssDNA observed in the RecA-ssDNA-ADP$\mathrm{AlF}_{4}$ crystal structure (Chen et al. 2008).

\section{HOMOLOGOUS RECOMBINATION BY EXONUCLEASES AND DNA-ANNEALING PROTEINS}

As illustrated by the dHJ and SDSA pathways, the relative simplicity of DNA annealing belies the complexity of DNA rearrangements that can be achieved when it is coupled to other processes. A case study is provided by reactions that occur when the activity of an annealing protein is coupled to that of an exonuclease. Several of these systems have been exploited for recombineering applications (Murphy 2012). Exonu- clease/annealing protein complexes promote DNA-pairing reactions that require neither a RecA-family protein nor ATP (Hall and Kolodner 1994; Kolodner et al. 1994; Passy et al. 1999; Reuven et al. 2003, 2004; Maresca et al. 2010). Examples include the E. coli RecE (Exo VIII) and RecT proteins, the bacteriophage $\lambda \operatorname{Red} \alpha$ ( $\lambda$ exo) and Red $\beta$ proteins, and the herpes simplex virus-1 UL12 (alkaline nuclease) and ICP8 proteins (Table 1). The annealing protein components (RecT, Red $\beta$, and ICP8) are not related to the RecA family, but are related to Rad52 (Passy et al. 1999; Iyer et al. 2002; Erler et al. 2009). Specific protein-protein interactions between the exonuclease and annealing protein partners appear to be important for recombination, even when the need for exonuclease activity is bypassed by using previously resected substrates (Muyrers et al. 2000; Reuven and Weller 2005). This suggests that the activities of the cognate exonuclease and annealing proteins are coordinated during recombination, as suggested by the observation that the ICP8 annealing protein increases the processivity of the UL12 exonuclease (Reuven and Weller 2005). The coordination of activities may provide a means to prevent the inhibition of recombination by SSB proteins, by excluding them from the resected intermediate.

Figure 5 illustrates a typical in vitro DNApairing reaction that is catalyzed by an annealing protein in combination with an exonuclease. Limited digestion of dsDNA ends by the exonuclease generates ssDNA tails, which the annealing protein anneals to a complementary ssDNA circle to generate a $\sigma$-form joint molecule. The annealing protein then promotes an ATP-independent DNA branch migration that converts the $\sigma$ form into an $\alpha$-form joint molecule. In some cases branch migration goes to completion, generating a gapped circular heteroduplex and a free linear single strand (Fig. 5). RecE and RecT form part of a minor recombination pathway encoded by a cryptic lambdoid prophage present in some strains of $E$. coli that is manifest in the absence of a functional RecBCD nuclease/ helicase complex (Clark et al. 1993; Kolodner et al. 1994). Studies of RecT suggest that despite its independent evolution, it shares with RecA 

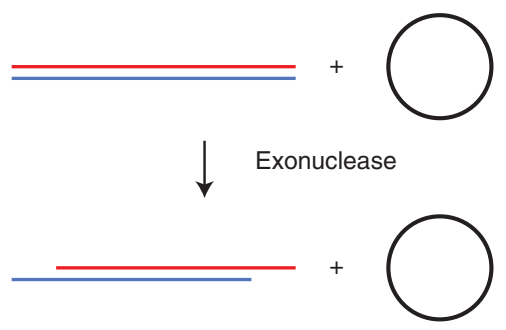

Annealing protein
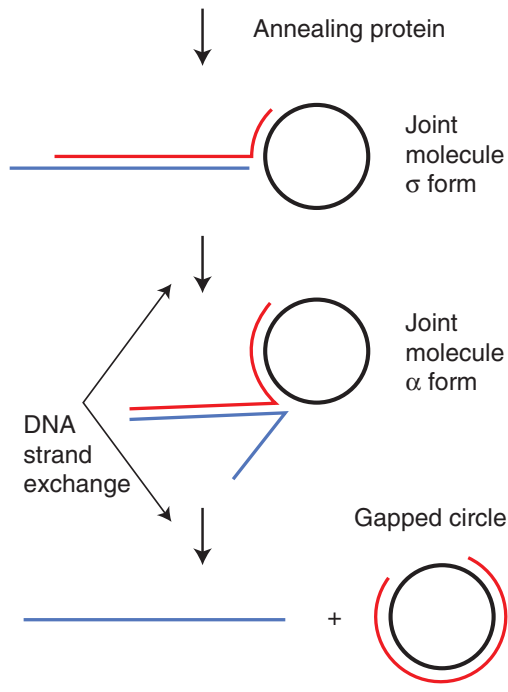

Figure 5. DNA pairing by exonuclease and annealing protein. The combined actions of an exonuclease and an annealing protein may give rise to DNA-pairing reactions that do not require a RecA-family recombinase or ATP. The schematic shows a standard in vitro assay system for measuring pairing promoted by an exonuclease and annealing protein. A linear duplex molecule undergoes partial digestion by the exonuclease component to generate ssDNA tails. One of these tails (red) is complementary to a circular ssDNA substrate (black) in the reaction mixture. The annealing protein component promotes annealing between the complementary ssDNA regions, generating a $\sigma$-form heteroduplex joint molecule. The annealing protein promotes branch migration of the $\sigma$ form to generate $\alpha$ forms and eventually a complete strand exchange with gapped circle and linear ssDNA as products.

some of the hallmarks of a homologous pairing protein, including the ability to unstack ssDNA bases, which may facilitate homologous contacts (Noirot et al. 2003). RecT shares the property with $\operatorname{Red} \beta$ and ICP8 of forming ringand filament-shaped structures in the presence of DNA (Thresher et al. 1995; Passy et al. 1999; Makhov and Griffith 2006; Makhov et al. 2009). The ring form of Red $\beta$ binds to ssDNA, whereas the helical form binds with higher affinity to the heteroduplex product of annealing (Karakousis et al. 1998; Passy et al. 1999), suggesting a mechanism for stabilizing the heteroduplex product of DNA strand exchange. These and many other observations support the notion that homology recognition provides such an evolutionary advantage that it has been selected for in completely different classes of proteins.

\section{CONCLUSION}

The formation of heteroduplex DNAvia pairing and annealing reactions is a fundamental biological process that is, paradoxically, necessary both for genome stability and for genome evolution. DNA-pairing and annealing reactions performed by RecA-family DNA-pairing proteins and their accessories (SSBs and RMPs), annealing proteins, and exonucleases are necessary for the high-fidelity repair of lesions, such as DNA DSBs using pathways, such as SDSA. Conversely, these same proteins may participate in repair processes, such as SSA that are directly mutagenic. The COs generated by pairing and annealing proteins during the $\mathrm{dHJ}$ process are desirable for meiotic recombination, but may be genotoxic in mitotic cells. The new frontier in understanding biological reactions that pair and anneal DNA is to understand the mechanisms that choose the correct recombination pathway for a given cellular context, and perhaps to manipulate recombination pathway choice for the betterment of human health.

\section{REFERENCES}

${ }^{*}$ Reference is also in this collection.

Amunugama R, Fishel R. 2012. Homologous recombination in eukaryotes. Prog Mol Biol Transl Sci 110: 155206.

Anand RP, Lovett ST, Haber JE. 2013. Break-induced DNA replication. Cold Spring Harb Perspect Biol 5: a010397.

Andersen SL, Sekelsky J. 2010. Meiotic versus mitotic recombination: Two different routes for double-strand break repair: The different functions of meiotic versus 
S.W. Morrical

mitotic DSB repair are reflected in different pathway usage and different outcomes. Bioessays 32: 1058-1066.

Arcus V. 2002. OB-fold domains: A snapshot of the evolution of sequence, structure and function. Curr Opin Struct Biol 12: 794-801.

Bascom-Slack CA, Ross LO, Dawson DS. 1997. Chiasmata, crossovers, and meiotic chromosome segregation. $A d v$ Genet 35: 253-284.

Baumann P, Benson FE, West SC. 1996. Human Rad51 protein promotes ATP-dependent homologous pairing and strand transfer reactions in vitro. Cell 87: 757-766.

Bazemore LR, Folta-Stogniew E, Takahashi M, Radding CM. 1997. RecA tests homology at both pairing and strand exchange. Proc Natl Acad Sci 94: 11863-11868.

Beernink HT, Morrical SW. 1998. The uvsY recombination protein of bacteriophage T4 forms hexamers in the presence and absence of single-stranded DNA. Biochemistry 37: 5673-5681.

Beernink HT, Morrical SW. 1999. RMPs: Recombination/ replication mediator proteins. Trends Biochem Sci 24: 385-389.

Bi B, Rybalchenko N, Golub EI, Radding CM. 2004. Human and yeast Rad52 proteins promote DNA strand exchange. Proc Natl Acad Sci 101: 9568-9572.

Bianco PR, Tracy RB, Kowalczykowski SC. 1998. DNA strand exchange proteins: A biochemical and physical comparison. Front Biosci 3: D570-D603.

Binz SK, Sheehan AM, Wold MS. 2004. Replication protein A phosphorylation and the cellular response to DNA damage. DNA Repair (Amst) 3: 1015-1024.

Bochkarev A, Bochkareva E. 2004. From RPA to BRCA2: Lessons from single-stranded DNA binding by the OBfold. Curr Opin Struct Biol 14: 36-42.

Bryant FR, Lehman IR. 1985. On the mechanism of renaturation of complementary DNA strands by the recA protein of Escherichia coli. Proc Natl Acad Sci 82: 297 301.

Ceballos SJ, Heyer WD. 2011. Functions of the Snf2/Swi2 family Rad54 motor protein in homologous recombination. Biochim Biophys Acta 1809: 509-523.

Cejka P, Plank JL, Bachrati CZ, Hickson ID, Kowalczykowski SC. 2010. Rmil stimulates decatenation of double Holliday junctions during dissolution by Sgs1-Top3. Nat Struct Mol Biol 17: 1377-1382.

Chen Z, Yang H, Pavletich NP. 2008. Mechanism of homologous recombination from the RecA-ssDNA/dsDNA structures. Nature 453: 489-494.

Chen J, Villanueva N, Rould MA, Morrical SW. 2010. Insights into the mechanism of Rad51 recombinase from the structure and properties of a filament interface mutant. Nucleic Acids Res 38: 4889-4906.

Clark AJ, Sharma V, Brenowitz S, Chu CC, Sandler S, Satin L, Templin A, Berger I, Cohen A. 1993. Genetic and molecular analyses of the $\mathrm{C}$-terminal region of the recE gene from the Rac prophage of Escherichia coli K-12 reveal the recT gene. J. Bacteriol 175: 7673-7682.

Compton SA, Ozgür S, Griffith JD. 2010. Ring-shaped Rad51 paralog protein complexes bind Holliday junctions and replication forks as visualized by electron microscopy. J Biol Chem 285: 13349-13356.
Conway AB, Lynch TW, Zhang Y, Fortin GS, Fung CW, Symington LS, Rice PA. 2004. Crystal structure of a Rad51 filament. Nat Struct Mol Biol 11: 791-796.

Cox MM. 1999. Recombinational DNA repair in bacteria and the RecA protein. Prog Nucleic Acid Res Mol Biol 63: $311-366$.

Cox MM. 2003. The bacterial RecA protein as a motor protein. Annu Rev Microbiol 57: 551-577.

Cox MM, Lehman IR. 1981. recA protein of Escherichia coli promotes branch migration, a kinetically distinct phase of DNA strand exchange. Proc Natl Acad Sci 78: 34333437.

Daley JM, Niu H, Sung P. 2013. Roles of DNA helicases in the mediation and regulation of homologous recombination. Adv Exp Med Biol 767: 185-202.

* Daley JM, Gaines WA, Kwon YH, Sung P. 2014. Regulation of DNA pairing in homologous recombination. Cold Spring Harb Perspect Biol 6: a017954.

DasGupta C, Wu AM, Kahn R, Cunningham RP, Radding CM. 1983. Concerted strand exchange and formation of Holliday structures by E. coli RecA protein. Cell 25: 507516.

Davis AP, Symington LS. 2001. The yeast recombinational repair protein Rad59 interacts with Rad52 and stimulates single-strand annealing. Genetics 159: 515-525.

Davis AP, Symington LS. 2003. The Rad52-Rad59 complex interacts with Rad51 and replication protein A. DNA Repair (Amst) 2: 1127-1134.

Deng X, Prakash A, Dhar K, Baia GS, Kolar C, Oakley GG, Borgstahl GE. 2009. Human replication protein ARad52-single-stranded DNA complex: Stoichiometry and evidence for strand transfer regulation by phosphorylation. Biochemistry 48: 6633-6643.

Dupaigne P, Le Breton C, Fabre F, Gangloff S, Le Cam E, Veaute X. 2008. The Srs 2 helicase activity is stimulated by Rad51 filaments on dsDNA: Implications for crossover incidence during mitotic recombination. Mol Cell 29: 243-254.

Erler A, Wegmann S, Elie-Caille C, Bradshaw CR, Maresca M, Seidel R, Habermann B, Muller DJ, Stewart AF. 2009. Conformational adaptability of $\operatorname{Red} \beta$ during DNA annealing and implications for its structural relationship with Rad52. J Mol Biol 391: 586-598.

Forget AL, Kowalczykowski SC. 2012. Single-molecule imaging of DNA pairing by RecA reveals a three-dimensional homology search. Nature 482: 423-427.

Formosa T, Alberts BM. 1986. DNA synthesis dependent on genetic recombination: Characterization of a reaction catalyzed by purified bacteriophage T4 proteins. Cell 47: 793-806.

Gajewski S, Webb MR, Galkin V, Egelman EH, Kreuzer KN, White SW. 2011. Crystal structure of the phage T4 recombinase UvsX and its functional interaction with the T4 SF2 helicase UvsW. J Mol Biol 405: 65-76.

Gerton JL, Hawley RS. 2005. Homologous chromosome interactions in meiosis: diversity amidst conservation. Nat Rev Genet 6: 477-487.

Gonda DK, Radding CM. 1986. The mechanism of the search for homology promoted by recA protein. Facilitated diffusion within nucleoprotein networks. J Biol Chem 261: 13087-13096. 
Griffith J, Formosa T. 1985. The uvsX protein of bacteriophage T4 arranges single-stranded and double-stranded DNA into similar helical nucleoprotein filaments. J Biol Chem 260: 4484-4491.

Grimme JM, Honda M, Wright R, Okuno Y, Rothenberg E, Mazin AV, Ha T, Spies M. 2010. Human Rad52 binds and wraps single-stranded DNA and mediates annealing via two hRad52-ssDNA complexes. Nucleic Acids Res 38: 2917-2930.

Gupta RC, Bazemore LR, Golub EI, Radding CM. 1997. Activities of human recombination protein Rad51. Proc Natl Acad Sci 94: 463-468.

Haber JE. 1992. Exploring the pathways of homologous recombination. Curr Opin Cell Biol 4: 401-412.

Hall SD, Kolodner RD. 1994. Homologous pairing and strand exchange promoted by the Escherichia coli RecT protein. Proc Natl Acad Sci 91: 3205-3209.

Harris LD, Griffith JD. 1989. UvsY protein of bacteriophage $\mathrm{T} 4$ is an accessory protein for in vitro catalysis of strand exchange. J Mol Biol 206: 19-27.

Hashimoto K, Yonesaki T. 1991. The characterization of a complex of three bacteriophage $\mathrm{T} 4$ recombination proteins, uvsX protein, uvsY protein, and gene 32 protein, on single-stranded DNA. J Biol Chem 266: 4883-4888.

Heyer WD, Li X, Rolfsmeier M, Zhang XP. 2006. Rad54: The Swiss Army knife of homologous recombination? Nucleic Acids Res 34: 4115-4125.

Hickson ID, Mankouri HW. 2011. Processing of homologous recombination repair intermediates by the Sgs1Top3-Rmil and Mus81-Mms4 complexes. Cell Cycle 10: 3078-3085.

Ira G, Malkova A, Liberi G, Foiani M, Haber JE. 2003. Srs2 and Sgs1-Top3 suppress crossovers during double-strand break repair in yeast. Cell 115: 401-411.

Iyer LM, Koonin EV, Aravind L. 2002. Classification and evolutionary history of the single-strand annealing proteins, RecT, Redbeta, ERF and RAD52. BMC Genomics 3: 8.

Jensen RB, Carreira A, Kowalczykowski SC. 2010. Purified human BRCA2 stimulates RAD51-mediated recombination. Nature 467: 678-683.

Kantake N, Madiraju MV, Sugiyama T, Kowalczykowski SC 2002. Escherichia coli RecO protein anneals ssDNA complexed with its cognate ssDNA-binding protein: A common step in genetic recombination. Proc Natl Acad Sci 99: $15327-15332$.

Karakousis G, Ye N, Li Z, Chiu SK, Reddy G, Radding CM. 1998 . The $\beta$ protein of phage $\lambda$ binds preferentially to an intermediate in DNA renaturation. J Mol Biol 276: 721731.

Kim JI, Cox MM, Inman RB. 1992. On the role of ATP hydrolysis in RecA protein-mediated DNA strand exchange. II. Four-strand exchanges. J Biol Chem 267: 16444-16449.

Kodadek T. 1990. The role of the bacteriophage T4 gene 32 protein in homologous pairing. J Biol Chem 265: 20966 20969.

Kodadek T, Wong ML, Alberts BM. 1988. The mechanism of homologous DNA strand exchange catalyzed by the bacteriophage T4 uvsX and gene 32 proteins. J Biol Chem 263: $9427-9436$.
Kodadek T, Gan DC, Stemke-Hale K. 1989. The phage T4 uvs $\mathrm{Y}$ recombination protein stabilizes presynaptic filaments. J Biol Chem 264: 16451-16457.

Kolodner R, Hall SD, Luisi-DeLuca C. 1994. Homologous pairing proteins encoded by the Escherichia coli recE and recT genes. Mol Microbiol 11: 23-30.

Kowalczykowski SC. 1991. Biochemistry of genetic recombination: Energetics and mechanism of DNA strand exchange. Annu Rev Biophys Biophys Chem 20: 539-575.

Kowalczykowski SC. 2008. Structural biology: Snapshots of DNA repair. Nature 453: 463-466.

Kreuzer KN. 2000. Recombination-dependent DNA replication in phage T4. Trends Biochem Sci 25: 165-173.

Kreuzer KN, Brister JR. 2010. Initiation of bacteriophage T4 DNA replication and replication fork dynamics: A review in the Virology Journal series on bacteriophage T4 and its relatives. Virol J 7: 358

Kumar JK, Gupta RC. 2004. Strand exchange activity of human recombination protein Rad52. Proc Natl Acad Sci 101: 9562-9567.

* Lam I, Keeney S. 2015. Mechanism and regulation of meiotic recombination initiation. Cold Spring Harb Perspect Biol 7: a016634.

Lee AM, Xiao J, Singleton SF. 2006. Origins of sequence selectivity in homologous genetic recombination: Insights from rapid kinetic probing of RecA-mediated DNA strand exchange. J Mol Biol 360: 343-359.

Li X, Heyer WD. 2009. RAD54 controls access to the invading $3^{\prime}-\mathrm{OH}$ end after RAD51-mediated DNA strand invasion in homologous recombination in Saccharomyces cerevisiae. Nucleic Acids Res 37: 638-646.

Li X, Zhang XP, Solinger JA, Kiianitsa K, Yu X, Egelman EH, Heyer WD. 2007. Rad51 and Rad54 ATPase activities are both required to modulate Rad51-dsDNA filament dynamics. Nucleic Acids Res 35: 4124-4140.

Liu J, Morrical SW. 2010. Assembly and dynamics of the bacteriophage T4 homologous recombination machinery. Virol J 7: 357.

Liu J, Qian N, Morrical SW. 2006. Dynamics of bacteriophage T4 presynaptic filament assembly from extrinsic fluorescence measurements of Gp32-single-stranded DNA interactions. J Biol Chem 281: 26308-26319.

Liu J, Doty T, Gibson B, Heyer WD. 2010. Human BRCA2 protein promotes RAD51 filament formation on RPAcovered single-stranded DNA. Nat Struct Mol Biol 17: $1260-1262$.

Liu J, Ehmsen KT, Heyer WD, Morrical SW. 2011a. Presynaptic filament dynamics in homologous recombination and DNA repair. Crit Rev Biochem Mol Biol 46: 240-270.

Liu J, Renault L, Veaute X, Fabre F, Stahlberg H, Heyer WD. 2011b. Rad51 paralogues Rad55-Rad57 balance the antirecombinase Srs2 in Rad51 filament formation. Nature 479: $245-248$.

Liu J, Berger CL, Morrical SW. 2013. Kinetics of presynaptic filament assembly in the presence of single-stranded DNA binding protein and recombination mediator protein. Biochemistry 52: 7878-7889.

Llorente B, Smith CE, Symington LS. 2008. Break-induced replication: What is it and what is it for? Cell Cycle 7: 859 864. 
S.W. Morrical

Lohman TM, Ferrari ME. 1994. Escherichia coli singlestranded DNA-binding protein: Multiple DNA-binding modes and cooperativities. Annu Rev Biochem 63: 527570.

Lohman TM, Bujalowski W, Overman LB. 1988. E. coli single strand binding protein: A new look at helix-destabilizing proteins. Trends Biochem Sci 13: 250-255.

Lydeard JR, Lipkin-Moore Z, Sheu YJ, Stillman B, Burgers PM, Haber JE. 2010. Break-induced replication requires all essential DNA replication factors except those specific for pre-RC assembly. Genes Dev 24: 1133-1144.

Maher RL, Morrical SW. 2013. Coordinated binding of single-stranded and double-stranded DNA by uvsX recombinase. PLOS ONR 8: e66654.

Maher RL, Branagan AM, Morrical SW. 2011. Coordination of DNA replication and recombination activities in the maintenance of genome stability. J Cell Biochem 112: 2672-2682.

Makhov AM, Griffith JD. 2006. Visualization of the annealing of complementary single-stranded DNA catalyzed by the herpes simplex virus type 1 ICP8 SSB/recombinase. J Mol Biol 355: 911-922.

Makhov AM, Sen A, Yu X, Simon MN, Griffith JD, Egelman EH. 2009. The bipolar filaments formed by herpes simplex virus type $1 \mathrm{SSB} /$ recombination protein (ICP8) suggest a mechanism for DNA annealing. J Mol Biol 386: 273-279.

Mankouri HW, Ashton TM, Hickson ID. 2011. Holliday junction-containing DNA structures persist in cells lacking Sgs1 or Top3 following exposure to DNA damage. Proc Natl Acad Sci 108: 4944-4949.

Maresca M, Erler A, Fu J, Friedrich A, Zhang Y, Stewart AF. 2010. Single-stranded heteroduplex intermediates in $\lambda$ Red homologous recombination. BMC Mol Biol 11: 54.

Masson JY, Tarsounas MC, Stasiak AZ, Stasiak A, Shah R, McIlwraith MJ, Benson FE, West SC. 2001. Identification and purification of two distinct complexes containing the five RAD51 paralogs. Genes Dev 15: 3296-3307.

Mazin AV, Kowalczykowski SC. 1996. The specificity of the secondary DNA binding site of RecA protein defines its role in DNA strand exchange. Proc Natl Acad Sci 93: 10673-10678.

Mazin AV, Kowalczykowski SC. 1998. The function of the secondary DNA-binding site of RecA protein during DNA strand exchange. EMBO J 17: 1161-1168.

Mazin AV, Alexeev AA, Kowalczykowski SC. 2003. A novel function of Rad54 protein. Stabilization of the Rad51 nucleoprotein filament. J Biol Chem 278: 14029-14036.

McEntee K. 1985. Kinetics of DNA renaturation catalyzed by the RecA protein of Escherichia coli. Biochemistry 24: 4345-4351.

McEntee K, Weinstock GM, Lehman IR. 1981. Binding of the recA protein of Escherichia coli to single- and doublestranded DNA. J Biol Chem 256: 8835-8844.

McIlwraith MJ, Van Dyck E, Masson JY, Stasiak AZ, Stasiak A, West SC. 2000. Reconstitution of the strand invasion step of double-strand break repair using human Rad51 Rad52 and RPA proteins. J Mol Biol 304: 151-164.

McMahill MS, Sham CW, Bishop DK. 2007. Synthesis-dependent strand annealing in meiosis. PLoS Biol 5: e299.
* Mehta A, Haber JE. 2014. Sources of DNA double-strand breaks and models for recombinational DNA repair. Cold Spring Harb Perspect Biol 6: a016428.

Menetski JP, Bear DG, Kowalczykowski SC. 1990. Stable DNA heteroduplex formation catalyzed by the Escherichia coli RecA protein in the absence of ATP hydrolysis. Proc Natl Acad Sci 87: 21-25.

Mimitou EP, Symington LS. 2009. DNA end resection: Many nucleases make light work. DNA Repair (Amst) 8: 983-995.

Mitchel K, Lehner K Jinks-Robertson S. 2013. Heteroduplex DNA position defines the roles of the Sgs1, Srs2, and $\mathrm{Mph} 1$ helicases in promoting distinct recombination outcomes. PLoS Genet 9: e1003340.

Miura T, Yamana Y, Usui T, Ogawa HI, Yamamoto MT, Kusano K. 2012. Homologous recombination via synthesisdependent strand annealing in yeast requires the Irc20 and Srs2 DNA helicases. Genetics 191: 65-78.

Morel P, Stasiak A, Ehrlich SD, Cassuto E. 1994. Effect of length and location of heterologous sequences on RecAmediated strand exchange. J Biol Chem 269: 1983019835.

Morimatsu K, Kowalczykowski SC. 2003. RecFOR proteins load RecA protein onto gapped DNA to accelerate DNA strand exchange: A universal step of recombinational repair. Mol Cell 11: 1337-1347.

Morrical SW, Alberts BM. 1990. The UvsY protein of bacteriophage T4 modulates recombination-dependent DNA synthesis in vitro. J Biol Chem 265: 15096-15103.

Mortensen UH, Bendixen C, Sunjevaric I, Rothstein R. 1996. DNA strand annealing is promoted by the yeast Rad52 protein. Proc Natl Acad Sci 93: 10729-10734.

Mueller JE, Clyman J, Huang YJ, Parker MM, Belfort M. 1996. Intron mobility in phage T4 occurs in the context of recombination-dependent DNA replication by way of multiple pathways. Genes Dev 10: 351-364.

Murphy KC. 2012. Phage recombinases and their applications. Adv Virus Res 83: 367-414.

Muyrers JP, Zhang Y, Buchholz F, Stewart AF. 2000. RecE/ $\operatorname{RecT}$ and $\operatorname{Red} \alpha / \operatorname{Red} \beta$ initiate double-stranded break repair by specifically interacting with their respective partners. Genes Dev 14: 1971-1982.

Navadgi VM, Dutta A, Rao BJ. 2003. Human Rad52 facilitates a three-stranded pairing that follows no strand exchange: A novel pairing function of the protein. Biochemistry 42: 15237-15251.

New JH, Sugiyama T, Zaitseva E, Kowalczykowski SC. 1998. Rad52 protein stimulates DNA strand exchange by Rad51 and replication protein A. Nature 391: 407-410.

Nimonkar AV, Kowalczykowski SC. 2009. Second-end DNA capture in double-strand break repair: How to catch a DNA by its tail. Cell Cycle 8: 1816-1817.

Nimonkar AV, Sica RA, Kowalczykowski SC. 2009. Rad52 promotes second-end DNA capture in double-stranded break repair to form complement-stabilized joint molecules. Proc Natl Acad Sci 106: 3077-3082.

Noirot P, Gupta RC, Radding CM, Kolodner RD. 2003. Hallmarks of homology recognition by RecA-like recombinases are exhibited by the unrelated Escherichia coli RecT protein. EMBO J 22: 324-334. 
Ogawa T, Yu X, Shinohara A, Egelman EH. 1993. Similarity of the yeast RAD51 filament to the bacterial RecA filament. Science 259: 1896-1899.

Pannunzio NR, Manthey GM, Bailis AM. 2008. RAD59 is required for efficient repair of simultaneous doublestrand breaks resulting in translocations in Saccharomyces cerevisiae. DNA Repair (Amst) 7: 788-800.

Pannunzio NR, Manthey GM, Bailis AM. 2010. RAD59 and RAD1 cooperate in translocation formation by singlestrand annealing in Saccharomyces cerevisiae. Curr Genet 56: $87-100$.

Passy SI, Yu X, Li Z, Radding CM, Egelman EH. 1999. Rings and filaments of $\beta$ protein from bacteriophage $\lambda$ suggest a superfamily of recombination proteins. Proc Natl Acad Sci 96: 4279-4284.

Pellegrini L, Yu DS, Lo T, Anand S, Lee M, Blundell TL, Venkitaraman AR. 2002. Insights into DNA recombination from the structure of a RAD51-BRCA2 complex. Nature 420: 287-293.

Petukhova G, Stratton SA, Sung P. 1999. Single strand DNA binding and annealing activities in the yeast recombination factor Rad59. J Biol Chem 274: 33839-33842.

Pugh BF, Cox MM. 1987a. Stable binding of recA protein to duplex DNA. Unraveling a paradox. J Biol Chem 262: 1326-1336.

Pugh BF, Cox MM. 1987b. recA protein binding to the heteroduplex product of DNA strand exchange. J Biol Chem 262: $1337-1343$.

Pugh BF, Cox MM. 1988. General mechanism for RecA protein binding to duplex DNA. J Mol Biol 203: 479-493.

Ragunathan K, Joo C, Ha T. 2011. Real-time observation of strand exchange reaction with high spatiotemporal resolution. Structure 19: 1064-1073.

Rambo RP, Williams GJ, Tainer JA. 2010. Achieving fidelity in homologous recombination despite extreme complexity: Informed decisions by molecular profiling. Mol Cell 40: $347-348$.

Raschle M, Van Komen S, Chi P, Ellenberger T, Sung P. 2004. Multiple interactions with the Rad51 recombinase govern the homologous recombination function of Rad54. J Biol Chem 279: 51973-51980.

Reddy G, Golub EI, Radding CM. 1997. Human Rad52 protein promotes single-strand DNA annealing followed by branch migration. Mutat Res 377: 53-59.

Reuven NB, Weller SK. 2005. Herpes simplex virus type 1 single-strand DNA binding protein ICP8 enhances the nuclease activity of the UL12 alkaline nuclease by increasing its processivity. J Virol 79: 9356-9358.

Reuven NB, Staire AE, Myers RS, Weller SK. 2003. The herpes simplex virus type 1 alkaline nuclease and singlestranded DNA binding protein mediate strand exchange in vitro. J Virol 77: 7425-7433.

Reuven NB, Willcox S, Griffith JD, Weller SK. 2004. Catalysis of strand exchange by the HSV-1 UL12 and ICP8 proteins: Potent ICP8 recombinase activity is revealed upon resection of dsDNA substrate by nuclease. J Mol Biol 342: 57-71.

Richard DJ, Bolderson E, Khanna KK. 2009. Multiple human single-stranded DNA binding proteins function in genome maintenance: Structural, biochemical and functional analysis. Crit Rev Biochem Mol Biol 44: 98-116.
Rosenberg M, Echols H. 1990. Differential recognition of ultraviolet lesions by RecA protein. Possible mechanism for preferential targeting of SOS mutagenesis to (6-4) dipyrimidine sites. J Biol Chem 265: 20641-20645.

Ryzhikov M, Korolev S. 2012. Structural studies of SSB interaction with RecO. Methods Mol Biol 922: 123-131.

Ryzhikov M, Koroleva O, Postnov D, Tran A, Korolev S. 2011. Mechanism of RecO recruitment to DNA by single-stranded DNA binding protein. Nucleic Acids Res 39: 6305-6314.

Sakofsky CJ, Ayyar S, Malkova A. 2012. Break-induced replication and genome stability. Biomolecules 2: 483-504.

San Filippo J, Sung P, Klein H. 2008. Mechanism of eukaryotic homologous recombination. Annu Rev Biochem 77: 229-257.

Savir Y, Tlusty T. 2010. RecA-mediated homology search as a nearly optimal signal detection system. Mol Cell 40: $388-$ 396.

* Schiller CB, Seifert FU, Linke-Winnebeck C, Hopfner KP 2014. Structural studies of DNA end detection and resection in homologous recombination. Cold Spring Harb Perspect Biol 6: a017962.

Shan Q, Bork JM, Webb BL, Inman RB, Cox MM. 1997. RecA protein filaments: End-dependent dissociation from ssDNA and stabilization by $\mathrm{RecO}$ and RecR proteins. J Mol Biol 265: 519-540.

Shin DS, Chahwan C, Huffman JL, Tainer JA. 2004. Structure and function of the double-strand break repair machinery. DNA Repair (Amst) 3: 863-873.

Shinohara A, Shinohara M, Ohta T, Matsuda S, Ogawa T. 1998. Rad52 forms ring structures and co-operates with RPA in single-strand DNA annealing. Genes Cells 3: 145156.

Solinger JA, Kiianitsa K, Heyer WD. 2002. Rad54, a Swi2/ Snf2-like recombinational repair protein, disassembles Rad51:dsDNA filaments. Mol Cell 10: 1175-1188.

Song B, Sung P. 2000. Functional interactions among yeast Rad51 recombinase, Rad52 mediator, and replication protein A in DNA strand exchange. J Biol Chem 275: 15895-15904.

Story RM, Weber IT, Steitz TA. 1992. The structure of the E. coli recA protein monomer and polymer. Nature 355: $318-325$.

Sugawara N, Ira G, Haber JE. 2000. DNA length dependence of the single-strand annealing pathway and the role of Saccharomyces cerevisiae RAD59 in double-strand break repair. Mol Cell Biol 20: 5300-5309.

Sugiyama T, Kowalczykowski SC. 2002. Rad52 protein associates with replication protein A (RPA)-single-stranded DNA to accelerate Rad51-mediated displacement of RPA and presynaptic complex formation. J Biol Chem 277: 31663-31672.

Sugiyama T, New JH, Kowalczykowski SC. 1998. DNA annealing by RAD52 protein is stimulated by specific interaction with the complex of replication protein $\mathrm{A}$ and single-stranded DNA. Proc Natl Acad Sci 95: 6049-6054.

Sung P. 1994. Catalysis of ATP-dependent homologous DNA pairing and strand exchange by yeast RAD51 protein. Science 265: 1241-1243.

Sung P. 1997a. Yeast Rad55 and Rad57 proteins form a heterodimer that functions with replication protein A to 
S.W. Morrical

promote DNA strand exchange by Rad51 recombinase. Genes Dev 11: 1111-1121.

Sung P. 1997b. Function of yeast Rad52 protein as a mediator between replication protein A and the Rad51 recombinase. J Biol Chem 272: 28194-28197.

Sung P, Robberson DL. 1995. DNA strand exchange mediated by a RAD51-ssDNA nucleoprotein filament with polarity opposite to that of RecA. Cell 82: 453-461.

Sweezy MA, Morrical SW. 1999. Biochemical interactions within a ternary complex of the bacteriophage T4 recombination proteins uvsYand gp 32 bound to single-stranded DNA. Biochemistry 38: 936-944.

Symington LS. 2002. Role of RAD52 epistasis group genes in homologous recombination and double-strand break repair. Microbiol Mol Biol Rev 66: 630-670.

* Symington LS. 2014. End section at double-strand breaks: Mechanism and regulation. Cold Spring Harb Perspect Biol 6: a016436.

Szostak JW, Orr-Weaver TL, Rothstein RJ, Stahl FW. 1983. The double-strand-break repair model for recombination. Cell 33: 25-35.

Takahashi M, Maraboeuf F, Morimatsu K, Selmane T, Fleury F, Norden B. 2007. Calorimetric analysis of binding of two consecutive DNA strands to RecA protein illuminates mechanism for recognition of homology. J Mol Biol 365: 603-611.

Thresher RJ, Makhov AM, Hall SD, Kolodner R, Griffith JD. 1995. Electron microscopic visualization of RecT protein and its complexes with DNA. J Mol Biol 254: 364-371.

Thomas CM, Nielsen KM. 2005. Mechanisms of, and barriers to, horizontal gene transfer between bacteria. Nat Rev Microbiol 3: 711-721.

Thorslund T, McIlwraith MJ, Compton SA, Lekomtsev S, Petronczki M, Griffith JD, West SC. 2010. The breast cancer tumor suppressor BRCA2 promotes the specific targeting of RAD51 to single-stranded DNA. Nat Struct Mol Biol 17: 1263-1265.

Tsaneva IR, Müller B, West SC. 1992. ATP-dependent branch migration of Holliday junctions promoted by the RuvA and RuvB proteins of E. coli. Cell 69: 1171-1180.

Umezu K, Kolodner RD. 1994. Protein interactions in genetic recombination in Escherichia coli. Interactions involving $\mathrm{RecO}$ and RecR overcome the inhibition of RecA by single-stranded DNA-binding protein. J Biol Chem 269: 30005-30013.

Umezu K, Chi NW, Kolodner RD. 1993. Biochemical interaction of the Escherichia coli RecF, RecO, and RecR proteins with RecA protein and single-stranded DNA binding protein. Proc Natl Acad Sci 90: 3875-3879.

Van Komen S, Petukhova G, Sigurdsson S, Sung P. 2002. Functional cross-talk among Rad51, Rad54, and replication protein A in heteroduplex DNA joint formation. $J$ Biol Chem 277: 43578-43587.
Wold MS. 1997. Replication protein A: A heterotrimeric, single-stranded DNA-binding protein required for eukaryotic DNA metabolism. Annu Rev Biochem 66: 61-92.

Wright WD, Heyer WD. 2014. Rad54 functions as a heteroduplex DNA pump modulated by its DNA substrates and Rad51 during D-loop formation. Mol Cell 53: 420-432.

Wu Y, He Y, Moya IA, Qian X, Luo Y. 2004. Crystal structure of archaeal recombinase RADA: A snapshot of its extended conformation. Mol Cell 15: 423-435.

Wu Y, Sugiyama T, Kowalczykowski SC. 2006. DNA annealing mediated by Rad52 and Rad59 proteins. J Biol Chem 281: 15441-15449.

Wu Y, Kantake N, Sugiyama T, Kowalczykowski SC. 2008. Rad51 protein controls Rad52-mediated DNA annealing. J Biol Chem 283: 14883-14892.

Xu H, Beernink HT, Morrical SW. 2010. DNA-binding properties of T4 UvsY recombination mediator protein: Polynucleotide wrapping promotes high-affinity binding to single-stranded DNA. Nucleic Acids Res 38: 4821-4833.

Yang S, VanLoock MS, Yu X, Egelman EH. 2001. Comparison of bacteriophage T4 UvsX and human Rad51 filaments suggests that RecA-like polymers may have evolved independently. J Mol Biol 312: 999-1009.

Yokoyama H, Sarai N, Kagawa W, Enomoto R, Shibata T, Kurumizaka H, Yokoyama S. 2004. Preferential binding to branched DNA strands and strand-annealing activity of the human Rad51B, Rad51C, Rad51D and Xrcc2 protein complex. Nucleic Acids Res 32: 2556-2565.

Yonesaki T, Minagawa T. 1989. Synergistic action of three recombination gene products of bacteriophage $\mathrm{T} 4$, uvsX, uvsY, and gene 32 proteins. J Biol Chem 264: 7814-7820.

Yu X, Egelman EH. 1992. Structural data suggest that the active and inactive forms of the RecA filament are not simply interconvertible. J Mol Biol 227: 334-346.

Yu X, Egelman EH. 1993. DNA conformation induced by the bacteriophage T4 UvsX protein appears identical to the conformation induced by the Escherichia coli RecA protein. J Mol Biol 232: 1-4.

Yu X, Jacobs SA, West SC, Ogawa T, Egelman EH. 2001. Domain structure and dynamics in the helical filaments formed by RecA and Rad51 on DNA. Proc Natl Acad Sci 98: 8419-8424.

Zaitseva EM, Zaitsev EN, Kowalczykowski SC. 1999. The DNA binding properties of Saccharomyces cerevisiae Rad51 protein. J Biol Chem 274: 2907-2915.

* Zelensky A, Kanaar R, Wyman C. 2014. Mediators of homologous DNA pairing. Cold Spring Harb Perspect Biol 6: a016451.

* Zickler D, Kleckner N. 2015. Recombination, pairing, and synapsis of homologs during meiosis. Cold Spring Harb Perspect Biol doi: 10.1101/cshperspect.a016626. 


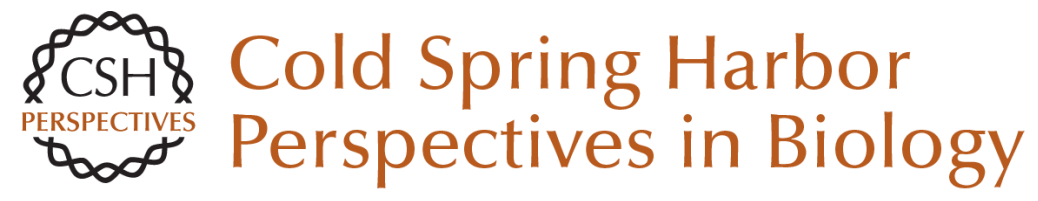

\section{DNA-Pairing and Annealing Processes in Homologous Recombination and Homology-Directed Repair}

Scott W. Morrical

Cold Spring Harb Perspect Biol 2015; doi: 10.1101/cshperspect.a016444

Subject Collection DNA Recombination

Meiotic Recombination: The Essence of Heredity Neil Hunter

Regulation of Recombination and Genomic Maintenance Wolf-Dietrich Heyer

Initiation of Meiotic Homologous Recombination: Flexibility, Impact of Histone Modifications, and Chromatin Remodeling Lóránt Székvölgyi, Kunihiro Ohta and Alain Nicolas

Mechanism and Regulation of Meiotic

Recombination Initiation Isabel Lam and Scott Keeney

Homologous Recombination and Human Health: The Roles of BRCA1, BRCA2, and Associated Proteins Rohit Prakash, Yu Zhang, Weiran Feng, et al.

Cell Biology of Mitotic Recombination Michael Lisby and Rodney Rothstein

DNA-Pairing and Annealing Processes in Homologous Recombination and Homology-Directed Repair Scott W. Morrical
An Overview of the Molecular Mechanisms of

Recombinational DNA Repair

Stephen C. Kowalczykowski

Recombination, Pairing, and Synapsis of Homologs during Meiosis

Denise Zickler and Nancy Kleckner

DNA Strand Exchange and RecA Homologs in

Meiosis

M. Scott Brown and Douglas K. Bishop

Meiosis and Maternal Aging: Insights from

Aneuploid Oocytes and Trisomy Births Mary Herbert, Dimitrios Kalleas, Daniel Cooney, et al.

Mismatch Repair during Homologous and

Homeologous Recombination Maria Spies and Richard Fishel

Mechanisms of Gene Duplication and

Amplification

Andrew B. Reams and John R. Roth

The Role of Double-Strand Break Repair Pathways at Functional and Dysfunctional Telomeres Ylli Doksani and Titia de Lange

For additional articles in this collection, see http://cshperspectives.cshlp.org/cgi/collection/

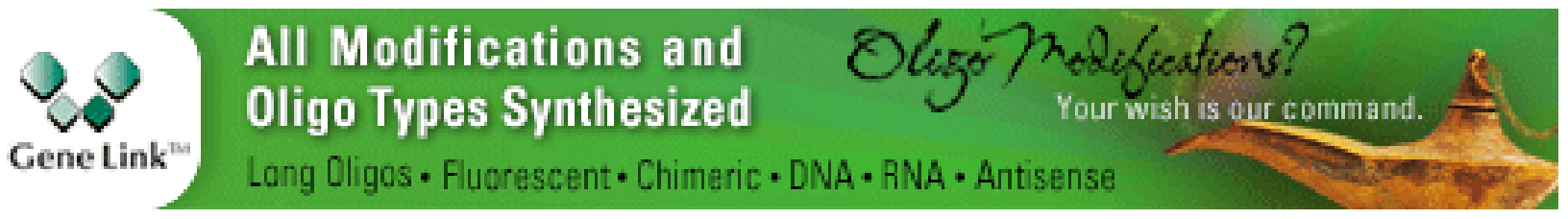




\section{Mediators of Homologous DNA Pairing}

Alex Zelensky, Roland Kanaar and Claire Wyman
Regulation of DNA Pairing in Homologous

Recombination

James M. Daley, William A. Gaines, YoungHo Kwon, et al.

For additional articles in this collection, see http://cshperspectives.cshlp.org/cgi/collection/

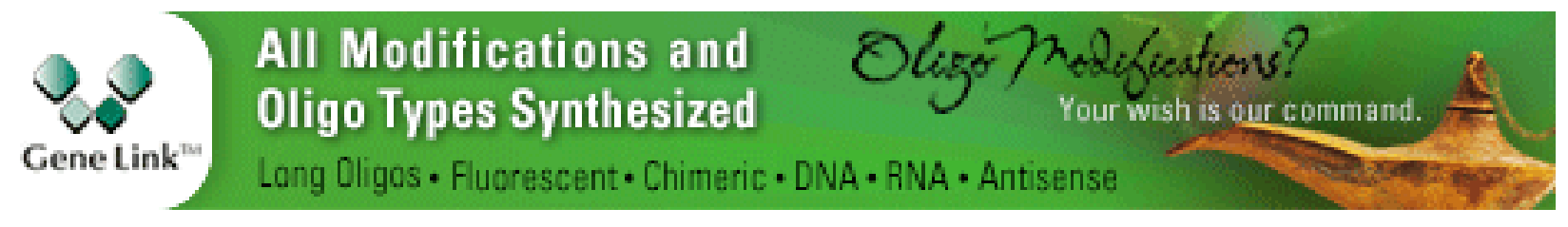

Copyright @ 2015 Cold Spring Harbor Laboratory Press; all rights reserved 